\title{
The emerging interface of mass spectrometry with materials
}

\author{
Papri Chakraborty ${ }^{1}$ and Thalappil Pradeep ${ }^{1}$
}

\begin{abstract}
Mass spectrometry (MS), a hundred-year-old subject, has been a technique of profound importance to molecular science. Its impact in solid-state materials science has not been evident, although many materials of modern science, such as fullerenes, have their origins in MS. Of late, mass spectrometric interface with materials is increasingly strengthened with advances in atomically precise clusters of noble metals. Advances in instrumentation along with recent developments in synthetic approaches have expanded the chemistry of clusters, and new insights into matter at the nanoscale are emerging. High-resolution MS coupled with soft ionization techniques enable efficient characterization of atomically precise clusters. Apart from that, techniques such as ion mobility, tandem MS, etc. reveal structural details of these systems. Growth, nucleation, and reactivity of clusters are also probed by MS. Some of the recent advancements in this field include the development of new hyphenated techniques. Finer structural details may be obtained by coupling MS with spectroscopic tools, such as photoelectron spectroscopy, vacuum ultraviolet spectroscopy, etc. With such advancements in instrumentation, MS can evolve into a universal tool for the characterization of materials. The present review captures highlights of this area.
\end{abstract}

\section{Introduction}

Mass spectrometry (MS), a century-old discipline concerning the investigation of matter using ions, is undergoing revolutionary changes. While the systems being examined went through systematic changes from atomic and molecular species to proteins and macromolecules in the course of evolution of MS, the perception of matter itself underwent a drastic transformation in this period. Materials science is becoming increasingly molecular today, and constituents of molecular matter are acquiring new properties leading to novel applications. Investigations require newer tools, and MS has evidently met the needs in this area. This has happened due to efficient methods of ionization of large molecular systems ${ }^{1,2}$.

The first use of MS dates back to a century ago when Sir J.J. Thomson measured the $\mathrm{m} / \mathrm{z}$ values of gaseous ionized molecules $^{3,4}$. He also found the first evidence of isotopes

Correspondence: Thalappil Pradeep (pradeep@iitm.ac.in)

'DST Unit of Nanoscience (DST UNS) and Thematic Unit of Excellence (TUE), Department of Chemistry, Indian Institute of Technology Madras, Chennai 600036 Tamil Nadu, India of an element ${ }^{5}$. Later in 1922, Aston received a Nobel Prize in Chemistry for his discovery of isotopes in several nonradioactive elements ${ }^{5}$. Initially, MS gained importance in the analysis of organic molecules, and ionization techniques like electric discharge and electron impact (EI) were used in such studies. Slowly, scientists started using MS for the analysis of sugars, alkaloids, and peptides ${ }^{6}$. The development of hyphenated techniques like gas chromatography-mass spectrometry $(\mathrm{GC}-\mathrm{MS})^{7,8}$ further strengthened the use of MS as an analytical tool. The use of tandem MS (MS/MS) techniques, where mass spectrum of a mass-selected species is analyzed, became a popular tool for understanding the structures of molecules. For extending MS/MS studies to larger molecules like proteins and peptides, Todd, McGilvery, and Baldwin constructed a high-resolution double-focussing mass spectrometer ${ }^{9}$. But still, MS/MS studies for large molecules were possible only with harsh ionization techniques like fast atom bombardment. For the study of large molecules like proteins, there was a need for the development of softer ionization techniques. Such needs led to 
the development of electrospray ionization (ESI) ${ }^{1}$, and for this breakthrough development, a Nobel Prize was awarded to John Fenn in 2002. Koichi Tanaka was also awarded a Nobel Prize in the same year for his development of soft laser desorption (SLD) and its applications for ionization of macromolecules ${ }^{10}$. Moreover, for the analysis of complex mixtures, high-resolving power $(\mathrm{m} /$ $\Delta \mathrm{m}$ ) is desired ${ }^{11}$. The use of time-of-flight (TOF) mass analyzers came into use in the year $1948^{12}$. By using dualstage reflectrons, the flight path of the ions could be extended by multiple reflections, and at present TOF analyzers can reach a resolving power of about 50,000 or more at $\mathrm{m} / \mathrm{z} 20-16,000$. In 1974, fourier-transform ion cyclotron resonance (FTICR) analyzers were introduced $^{13}$, which exhibited higher-resolving power compared with the TOF analyzers ${ }^{14}$. The orbitrap was invented in $1999^{14}$, and at present, they can reach a resolution of $6,00,000$ at $\mathrm{m} / \mathrm{z} 195^{15}$. The gas-phase ions generated inside the mass spectrometer can also be confined for a significant amount of time in "ion traps", and properties of the trapped ions have been studied in the literature ${ }^{16}$. Though MS is mainly used for proteomics these days, it also became popular for studying materials. In this review, we have captured how MS has enriched the field of materials science.

Extended solids have been the materials of recent past. They had unique tools for structural characterization, principally revolving around diffraction techniques of various forms ${ }^{17}$. The molecular systems on the other extreme had MS as their integral or most essential tool for compositional (to a lesser degree structural as well) analysis. As extended solids became molecular in their building blocks, as evident from the recent advances in nanoscale matter, analytical requirements to understand composition reached newer scales. Molecular materials of the past were composed of smaller constituents weighing a few hundred mass units. Many of them were stable under the harsh conditions of electron impact MS, and therefore were investigated extensively using sector-based instruments. Coupled with methods of ion activation, fragmentation gave a wealth of information on molecular structure $^{18}$. These studies were complemented by nuclear magnetic resonance (NMR) spectroscopy, and structural details of molecules with NMR active nuclei could be understood with precision ${ }^{19,20}$. This was expanded to even solution-state structure determination of macromolecules. The other extreme of structural insight came from electron diffraction, which was instrumental in understanding structures of simple molecules at the early part of the last century ${ }^{21}$. Soon, structural details of small molecules in the gas phase were understood mostly by spectroscopy, particularly for those molecules in the atmosphere as well as in interstellar space. Electron diffraction of another kind became a prominent analytical tool with the advent of electron microscopy (EM). With cryo-EM in low-dose diffraction, structures were being solved at Angstrom ( $\AA$ ) resolution in conjunction with high-quality modeling. In addition to single-crystal diffraction, NMR, electron diffraction, and spectroscopy, there are a number of scattering and analytical tools involving $\mathrm{X}$-rays, electrons, positrons, neutrons, photons, and ions to unravel the structure and properties of materials. While this review does not intend to cover comprehensively any of these techniques, we wish to note that the evolution of materials demands new kinds of techniques for compositional and structural analysis. This has happened because constituent units in advanced materials became more and more discrete while increasing in complexity. Along with this change, constituents of matter expanded from diatomics to polyatomics to macromolecules to nanoparticles. While the need to study all of them in isolation became intense, experimental methods of MS in ionization and ion analysis also got evolved.

The importance of MS as a tool for characterization of materials ${ }^{22-24}$ has got strengthened with the advancement in the science of atomically precise nanoclusters $(\mathrm{NCs})^{25,26}$, which are materials with atomic precision. Such clusters exhibit unique electronic and optical properties, and have precision in its compositional structure in the metal core and the protecting ligand layers. Till date, single-crystal X-ray crystallography has been used to resolve the structures of several clusters like $\mathrm{Au}_{25} \mathrm{~L}_{18}{ }^{27}, \mathrm{Au}_{28} \mathrm{~L}_{20}{ }^{28}, \mathrm{Au}_{38} \mathrm{~L}_{24}{ }^{29}, \mathrm{Au}_{40} \mathrm{~L}_{24}{ }^{30}, \mathrm{Au}_{52} \mathrm{~L}_{32}{ }^{31}$, $\mathrm{Au}_{92} \mathrm{~L}_{44}{ }^{32}, \mathrm{Au}_{102} \mathrm{~L}_{44}{ }^{33}, \mathrm{Au}_{133} \mathrm{~L}_{52}{ }^{34^{\prime}}, \mathrm{Ag}_{44} \mathrm{~L}_{30}{ }^{35}, \mathrm{Ag}_{25} \mathrm{~L}_{18}{ }^{36}$, $\mathrm{Ag}_{29} \mathrm{~L}_{12}{ }^{37}$, etc., where $\mathrm{L}$ corresponds to different types of ligands. However, due to their extremely small size, size determination by other techniques like transmission electronic microscopy (TEM) or powder XRD has been less reliable. In contrast, MS can accurately identify precision in their compositions. Techniques such as ion mobility-MS (IM-MS) and tandem MS (MS/MS) are becoming increasingly important for understanding the size, shape, and dynamics of cluster systems. Moreover, advancement in instrumentation has enabled the determination of inherent properties of clusters like electron affinity (EA), ionization energy (IE), electronic transitions, etc., through the development of new hyphenated techniques. In this review, we will discuss the recent advances in those emerging directions, and elucidate how MS is evolving into a promising tool for materials characterization.

This has become possible due to advancements in various areas of ionization, mass analysis, detection, sensitivity, resolution, etc. The landmark developments in these aspects are captured in Table 1. 
Table 1 Landmark events in the history of mass spectrometry and their importance in enabling the characterization of materials

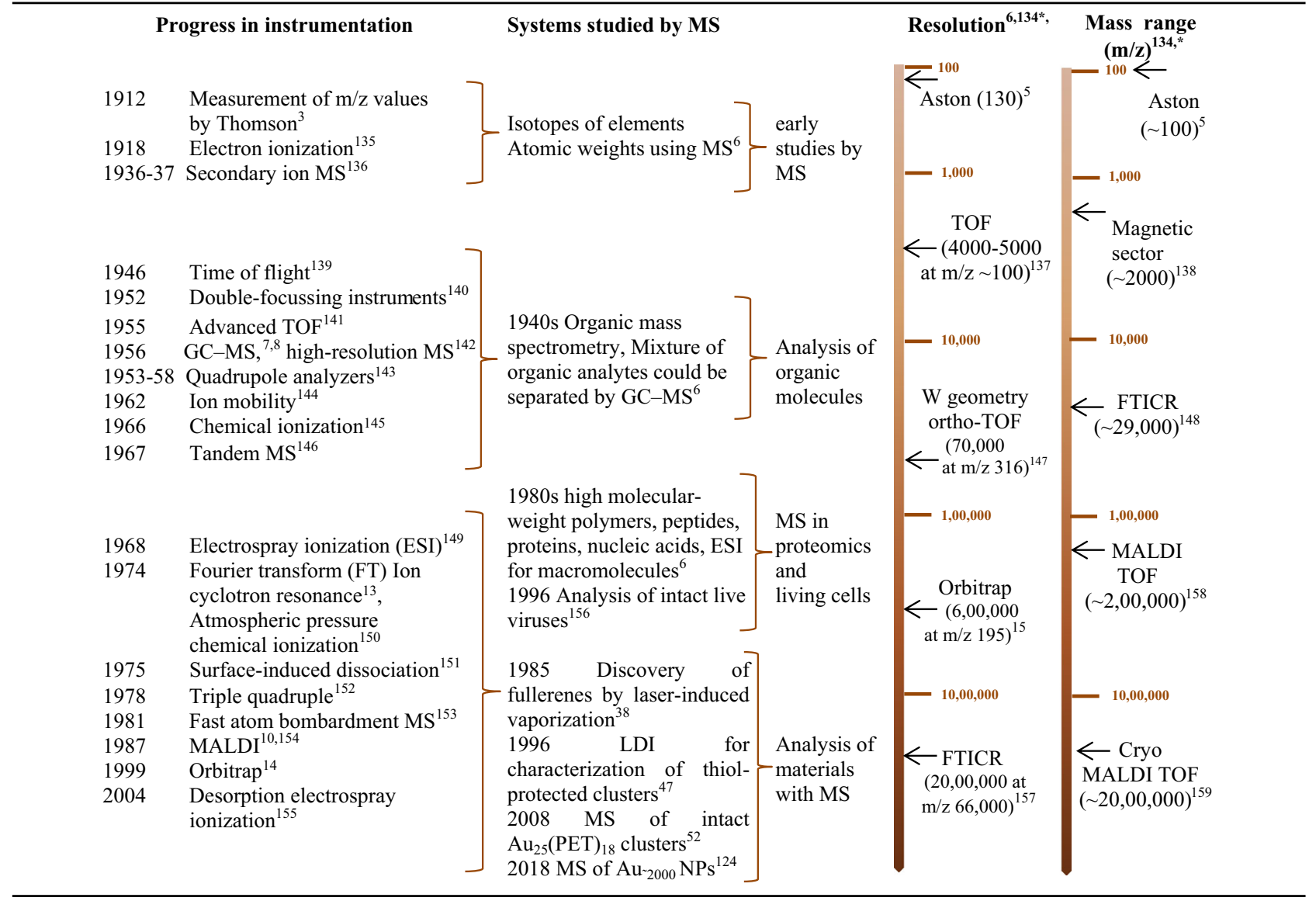

"Does not strictly correspond to the time evolution presented in the left column

\section{Role of MS in the discovery and characterization of materials}

One of the most popular classes of materials of modern science, fullerenes, was discovered using a mass spectrometer $^{38}$. When a pulsed laser evaporated a solid disk of graphite, cooling of the resulting carbon species by a highdensity helium flow resulted in the formation of carbon clusters, which were then detected by a TOF MS (Fig. $1 a)^{38}$. In low density of He gas, even numbered clusters, $\mathrm{C}_{\mathrm{n}}(n=38-120)$ were formed (Fig. 1(iii)), with increase in the He pressure to $\sim 760$ torr, the abundances of the peaks due to $\mathrm{C}_{60}$ and $\mathrm{C}_{70}$ were increased (Fig. 1ii) and the peak for $\mathrm{C}_{60}$ became predominant upon maximizing the cluster-cluster reactions and thermalization (Fig. 1(i)). Apart from fullerenes, MS was immensely used for the characterization of gas-phase metal clusters of $\mathrm{Na}$, namely $\mathrm{Na}_{n}(n=4-100)^{39}$. The discontinuous intensities for the clusters of $n=8,20,40,58$, and 92 observed in MS (Fig. 1b) were attributed to the stability of closed shell electronic configurations. Apart from that, there has been extensive research in the field of gas-phase semiconductor clusters like Si clusters $(n=8-24)$ (Fig. 1c) ${ }^{40}$ and molecular clusters like $\mathrm{MoS}_{2}$ clusters (Fig. 1d) ${ }^{41}$.

\section{Early stages of characterization of noble metal clusters by MS}

Gas-phase clusters of noble metals like $\mathrm{Au}_{\mathrm{n}}$ or $\mathrm{Ag}_{\mathrm{n}}$ were also investigated by $\mathrm{MS}^{42}$. Furche et al. assigned the structures of $\mathrm{Au}_{\mathrm{n}}(n<13)$ clusters by a combination of mass spectrometric and theoretical studies ${ }^{43}$. Lechtken et al. determined the structures of $\mathrm{Au}_{14}{ }^{-}-\mathrm{Au}_{19}{ }^{-}$clusters by trapped ion electron diffraction ${ }^{44}$. Later, in 2003, Li et al. observed that $\mathrm{Au}_{20}$ cluster which possesses a tetrahedral structure, shows similar atomic packing but largely different properties compared with bulk gold ${ }^{45}$. By photoelectron spectroscopy (PES), the authors 


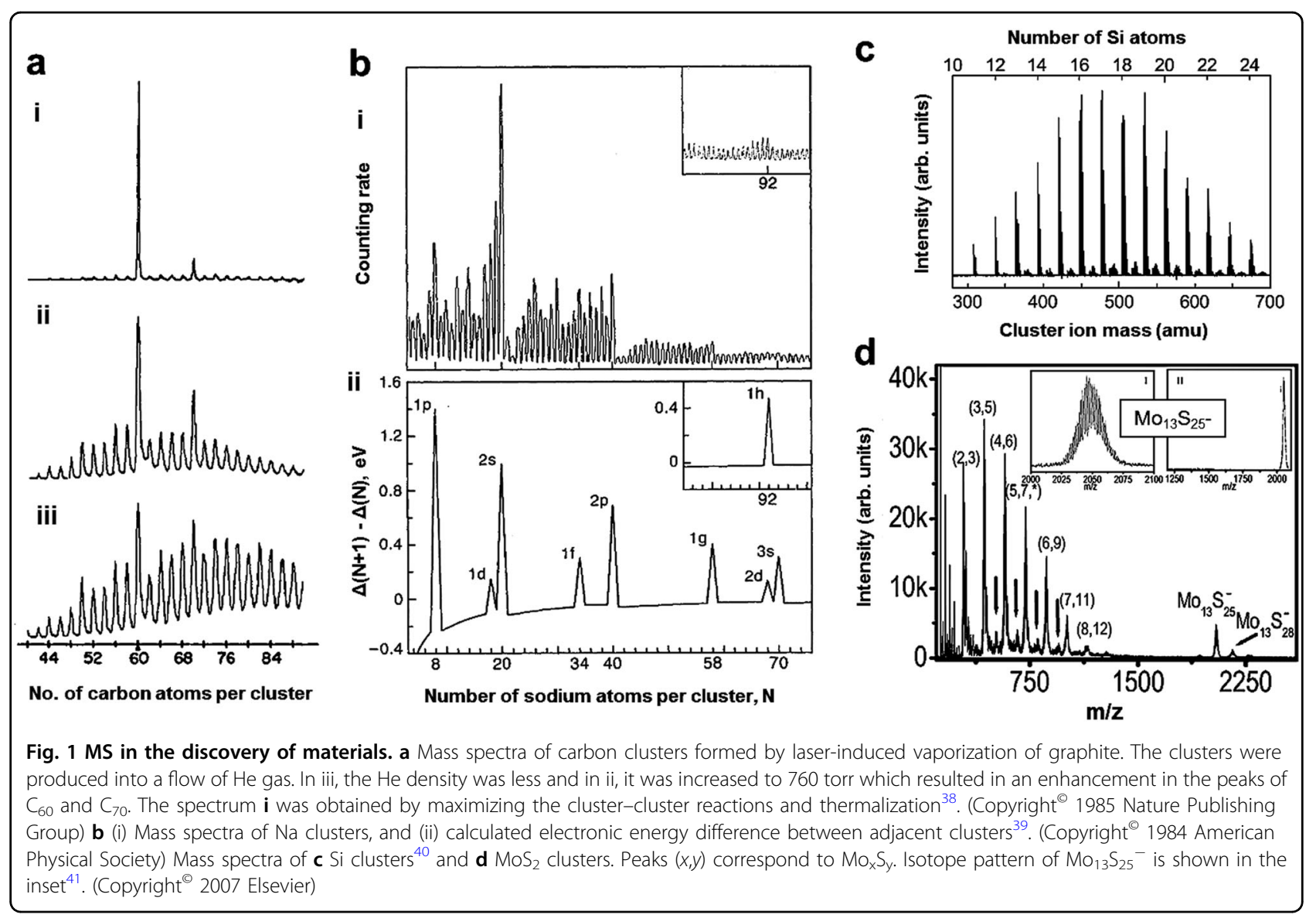

demonstrated that the $\mathrm{EA}$ of $\mathrm{Au}_{20}$ cluster was comparable with that of $\mathrm{C}_{60}$, as shown in Fig. 2a. Along with such studies on gas-phase bare metal clusters, MS slowly evolved into a powerful tool for the characterization of ligand-protected noble metal NCs also.

After Brust reported a new method of synthesis of thiolprotected gold NPs in $1994^{46}$, scientists started the synthesis of monodisperse NPs with molecule-like optical absorption features. In 1996, Whetten et al. used laser desorption ionization (LDI) for the characterization of dodecanethiol protected gold NCs having mass in the range of $27-93 \mathrm{kDa}$ (Fig. $2 \mathrm{~b})^{47}$. The LDI measurements suggested that the gold cores consisted of 140-459 atoms, which was also consistent with their TEM measurements.

\section{Advances in the study of noble metal clusters}

Though LDI was used as the primary characterization tool in the 1990s, softer techniques like matrix-assisted laser desorption ionization (MALDI) and ESI became more popular for the ionization of intact ligand-protected clusters. In 1998, Schaff et al. reported a $10.4 \mathrm{kDa} \mathrm{Au}-$ GSH $\left(\mathrm{GSH}=\right.$ glutathione) cluster, $\mathrm{Au}_{28}(\mathrm{SG})_{16}{ }^{48}$. The composition was proposed from both MALDI MS and ESI MS. Following this, several other reports came on the same cluster until in 2005, it was reassigned as $\mathrm{Au}_{25}(\mathrm{SG})_{18}$ by Negishi et al. ${ }^{49}$. With advancement in instrumentation, resolution of the mass spectral measurements improved, which enabled successful characterization of the cluster. MS has largely been used in the characterization of gold clusters, particularly due to their high stability under ambient conditions. Though ESI efficiently ionized watersoluble gold clusters, organic-soluble clusters often showed poor ionization efficiency in this technique. In order to overcome this, scientists implemented new approaches like ligand exchange with ionizable ligands ${ }^{50}$, using $\mathrm{Ce}\left(\mathrm{SO}_{4}\right)_{2}{ }^{51}$, or $\mathrm{CsOAc}$ to enhance the ionization $^{52,53}$. In most cases, with the choice of appropriate matrices like sinapinic acid, cinnamic acid, etc., MALDI worked better for the ionization of NCs. In 2008, Dass et al. introduced the use of trans-2-[3-(4-tert-butylphenyl)-2-methyl-2-propenylidene] malononitrile (DCTB) matrix which proved to be more effective ${ }^{52}$, and MALDI MS of intact $\mathrm{Au}_{25}(\mathrm{PET})_{18}$ clusters was successfully measured (Fig. 3b). Comparison of MALDI MS of $\mathrm{Au}_{25}(\mathrm{PET})_{18}$ clusters in different matrices showed the superiority of using DCTB (Fig. 3a). Larger NCs like $\mathrm{Au}_{102}(\mathrm{pMBA})_{44}{ }^{54}$ were also characterized using a combination of ESI and MALDI MS. However, due to lesser 

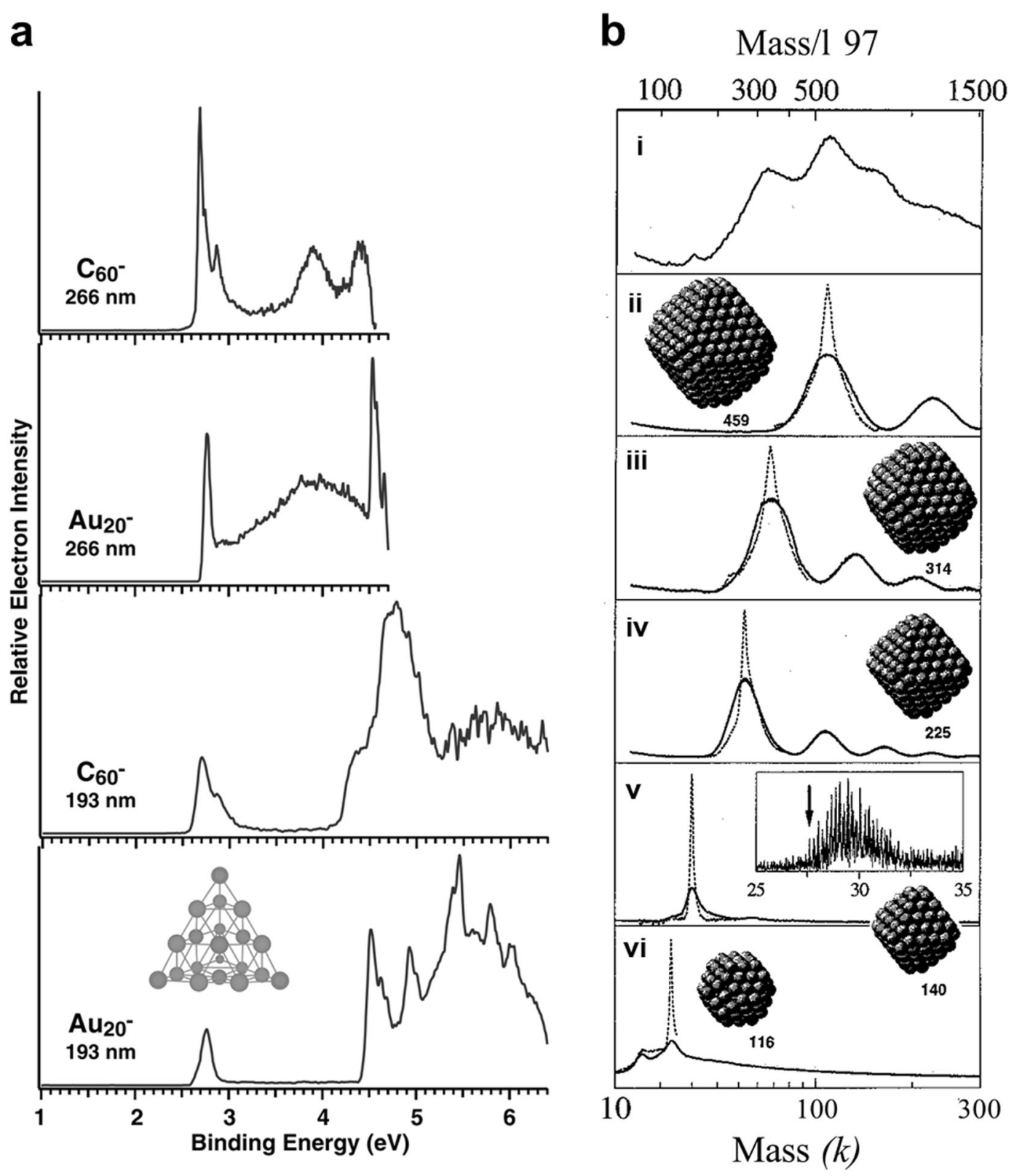

Fig. 2 Early stages of MS of noble metal clusters. a Photoelectron spectra of $\mathrm{Au}_{20}{ }^{-}$cluster compared with $\mathrm{C}_{60}{ }^{-}$at $193 \mathrm{~nm}$ and $266 \mathrm{~nm}{ }^{45}$. (Copyright ${ }^{\odot} 2003$ the American Association for the Advancement of Science) b Mass spectra obtained by laser desorption ionization of dodecanethiol thiol-protected gold clusters, (i) crude mixture of clusters and (ii-vi) separated fractions ${ }^{47}$. (Copyright ${ }^{\odot} 1996$ John Wiley and Sons)

stability, mass spectral characterization of silver clusters has always been challenging. As Ag has two isotopes (107 and 109), silver clusters show broader isotope patterns. At the initial stages of research in the field of Ag clusters, mercaptosuccinic acid $\left(\mathrm{H}_{2} \mathrm{MSA}\right)$ protected $\mathrm{Ag}_{7}, \mathrm{Ag}_{8}{ }^{55,56}$, glutathione protected $\mathrm{Ag}_{11}(\mathrm{SG})_{7}{ }^{57}, \mathrm{Ag}_{15}(\mathrm{SG})_{11}{ }^{58}$, $\mathrm{Ag}_{31}(\mathrm{SG})_{19}{ }^{58}$, and $\mathrm{Ag}_{32}(\mathrm{SG})_{19}{ }^{59}$, etc., clusters were characterized by MS. In 2012, Harkness et al. reported the $\mathrm{Ag}_{44}(\mathrm{SR})_{30} \mathrm{NCs}^{60}$, which was later crystallized in 2013 by Desireddy et al. ${ }^{35}$ and Yang et al. ${ }^{61}$. Recently, in 2015,
Bakr et al. reported $\mathrm{Ag}_{25}(\mathrm{SR})_{18} \mathrm{NCs}$ which exhibits identical structure as that of $\mathrm{Au}_{25}(\mathrm{SR})_{18}{ }^{36}$. A luminescent $\mathrm{Ag} \mathrm{NC}, \quad\left[\mathrm{Ag}_{29}(\mathrm{BDT})_{12}(\mathrm{TPP})_{4}\right]^{37}$, and a box-shaped $\left[\mathrm{Ag}_{67}\left(\mathrm{SPhMe}_{2}\right)_{32}\left(\mathrm{PPh}_{3}\right)_{8}\right]^{62}$ were also reported from the same group. High-resolution ESI MS gave the accurate molecular formulae of these clusters, which matched exactly with their composition found in crystal structures. This highlights the importance of using MS as a versatile tool for the characterization of the NCs. Most recently it has been possible to characterize new types of silver 


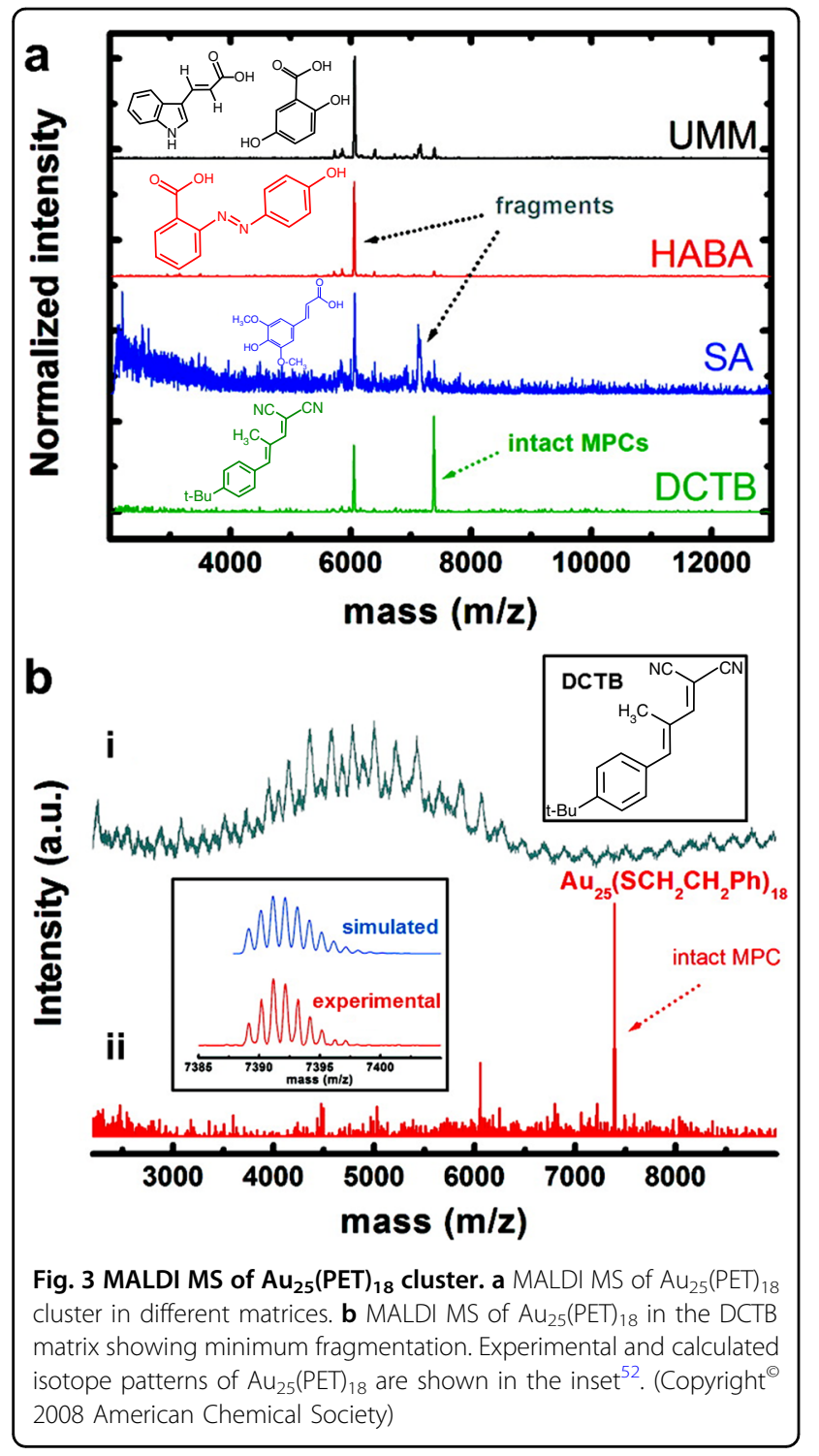

clusters, $\left[\mathrm{Ag}_{18} \mathrm{H}_{16}(\mathrm{TPP})_{10}\right]^{2+}, \quad\left[\mathrm{Ag}_{25} \mathrm{H}_{22}(\mathrm{DPPE})_{8}\right]^{3+}$, and $\left.\left[\mathrm{Ag}_{26} \mathrm{H}_{22} \text { (TFPP }\right)_{13}\right]^{2+}$, which are protected by hydrides and phosphines ${ }^{63}$. Hydride-doped gold cluster $\left[\mathrm{Au}_{9} \mathrm{H}\right.$ $\left.\left(\mathrm{PPh}_{3}\right)_{8}\right]^{2+64}$ and bimetallic $\left[\mathrm{HPdAu}_{9}\left(\mathrm{PPh}_{3}\right)_{8}\right]^{2+}$ clusters ${ }^{65}$ were also characterized by ESI MS. The crystal structures of many such clusters are not yet available.

Apart from research in the field of Au and Ag NCs, the applicability of MS has also been extended to the field of clusters of other noble metals, eg., $\mathrm{Pt} \mathrm{NCs}{ }^{66,67}, \mathrm{Pd} \mathrm{NCs}^{68-70}$. MS has also been proved to be useful in case of non-noble metals; eg. Cu NCs like $\left[\mathrm{Cu}_{20} \mathrm{H}_{11}\left(\mathrm{~S}_{2} \mathrm{P}(\mathrm{OiPr})_{2}\right)_{9}\right]^{71}$, Fe NCs like $\left[\mathrm{Fe}_{6} \mathrm{H}_{10}\left(\mathrm{PMe}_{3}\right)_{8}\right]^{+72}$, Ir NCs like $\operatorname{Ir}_{9}(\mathrm{PET})_{6}{ }^{73}$, etc.

\section{High-resolution mass spectrometry (HRMS)}

Over the years, there has been a tremendous improvement in instrumentation, which has enabled to obtain HR mass spectra of clusters with minimum fragmentation. A schematic of a HRMS instrument is shown in Fig. 4a. In the TOF analyzer, the trajectory of the ions can be controlled in a shorter "V" or a longer "W" path. With the increase in the path of the ions, the resolution $(\mathrm{m} / \Delta \mathrm{m})$ increases from $\sim 20,000-35,000$ to $\sim 35,000-50,000$ in the $\mathrm{m} / \mathrm{z}$ range of $20-16000$. Additional parts like "stepwaves" are used to remove all contaminants before the ions enter the quadrupole of the mass spectrometer. This also increases the sensitivity of the measurement. Precise composition of the core and the ligands and charge states of the cluster can be determined accurately by using HRMS. The compositions are further confirmed from the isotope patterns of the metals ( $\mathrm{Au}, \mathrm{Ag}, \mathrm{Pt}, \mathrm{Pd}$, etc.) and that of $\mathrm{C}, \mathrm{H}$, and $\mathrm{S}$ present in the ligands. HR ESI MS of $\mathrm{Au}_{25}(\mathrm{PET})_{18}{ }^{-}$(PET is phenyl ethane thiol) and $\mathrm{Ag}_{25}(\mathrm{DMBT})_{18}{ }^{-}$(DMBT is 2,4-dimethyl benzene thiol) are presented in Fig. $4 \mathrm{~b}$.

Apart from the conventional ESI MS analysis, HR mass spectrometers of the present day are also equipped with several other advanced features that enable further studies on the gas-phase cluster ions. Some such recent studies are summarized below.

\section{Ion mobility-mass spectrometry (IM-MS)}

MS coupled with IM has proved to be an important tool for structural characterization, and has enhanced research in many areas of biochemical and biophysical studies ${ }^{74}$. In the IM cell, the ions are passed through buffer gases like $\mathrm{He}, \mathrm{N}_{2}$, etc. As a result, species having the same mass but different size and shape exhibit different collision crosssection (CCS), hence show different drift times and get separated. IM-MS is capable of studying the conformational dynamics present in a system, and has largely been used to understand the folding and unfolding mechanism in proteins ${ }^{75}$. In materials science, IM-MS has been used to study the mechanism of formation of fullerenes from polycyclic aromatic hydrocarbons (PAH). Laser desorption of PAHs like $\mathrm{C}_{60} \mathrm{H}_{21} \mathrm{~F}_{9}{ }^{-}$causes stepwise loss of $\mathrm{HF}$ and $\mathrm{H}_{2}$ (Fig. 5ai), which results in increasing curvature of the remaining $\mathrm{PAH}$ fragments and finally closed-cage fullerenes are formed ${ }^{76}$. To understand the mechanism, the extent of curvature in the structure of the products at each step was modeled by comparing the CCS of the computed structures with the experimental CCS observed in IM-MS (Fig. 5aii). IM-MS has also been largely used for understanding the structures of polyoxometallates. Surman et al. showed that Keggin or Dawson type POM clusters (structures are shown in Fig. 5bi) can be used as IM calibrants for high mass negatively charged ions, and using the calibration curves (Fig. 5bii), structures of other POM clusters can be determined ${ }^{77}$.

Recently, IM-MS has also gained importance in the field of protected noble metal NCs. Baksi et al. separated dimers and trimers of $\left[\mathrm{Au}_{25}(\mathrm{SR})_{18}\right]^{-}$using $\mathrm{IM}-\mathrm{MS}^{78}$. A 

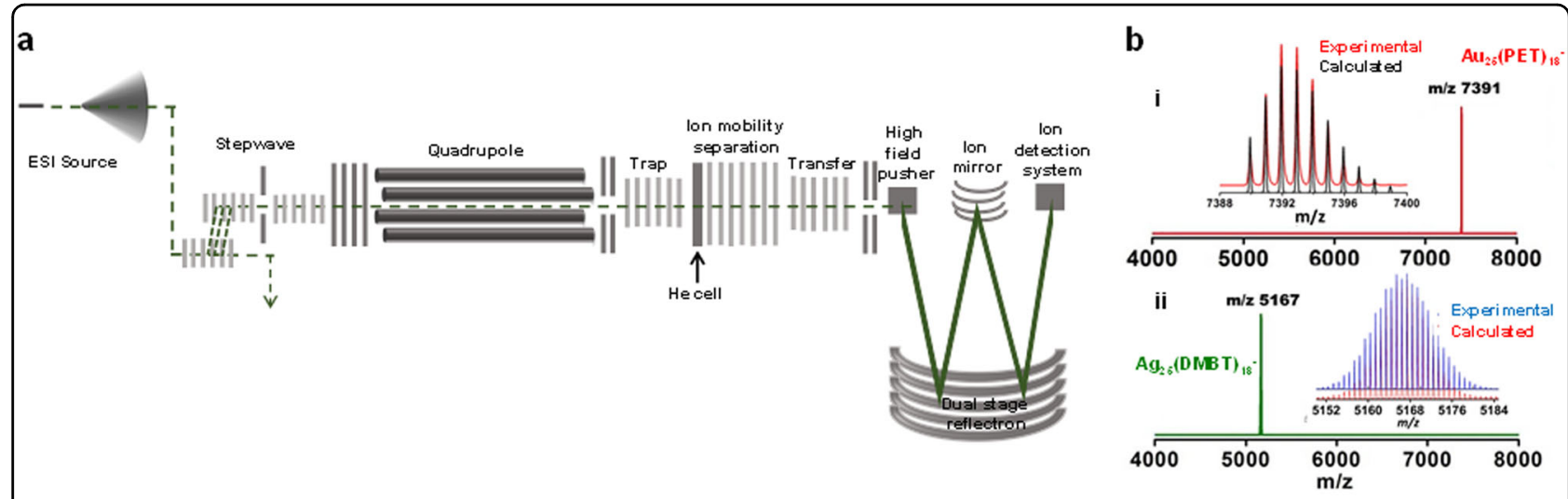

Fig. 4 High-resolution mass spectrometry (HRMS). a Schematic ion optics of a HR mass spectrometer. $\mathbf{b}$ HR ESI MS of (i) $\mathrm{Au}_{25}$ (PET) $18^{-}$and (ii) $\mathrm{Ag}_{25}(\mathrm{DMBT}){ }_{18}{ }^{-}$. Comparison of the experimental and calculated isotope patterns is presented in the insets ${ }^{110}$. (Copyright ${ }^{\circ} 2016$ Nature $^{\circ}$ Publishing Group)
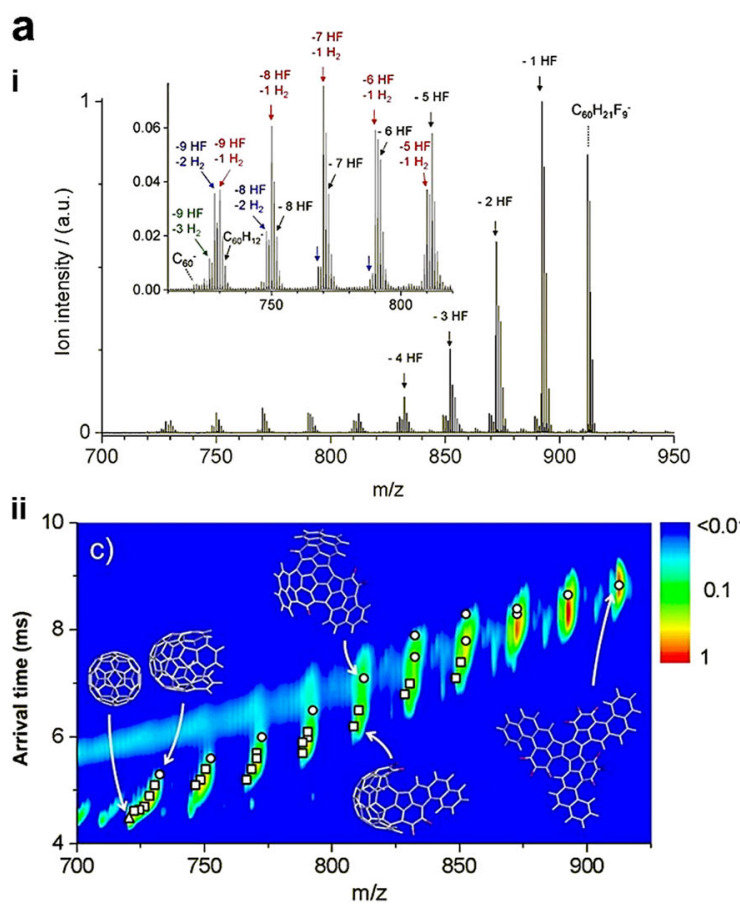

b

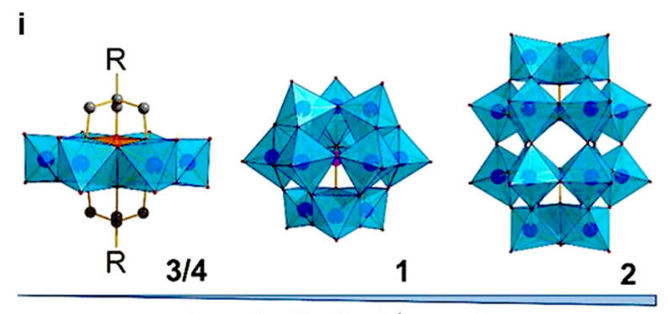

Increasing Size $(6-12 A$ approx.)

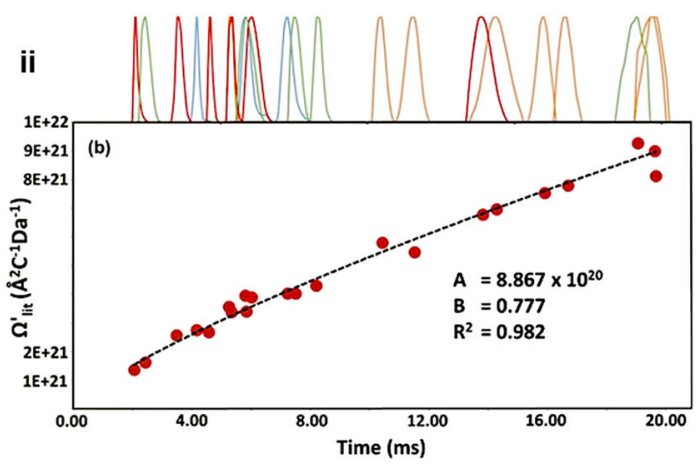

Fig. $5 \mathrm{IM}$ studies on fullerenes and polyoxometallates. a (i) Mass spectra obtained by laser-induced ionization of $\mathrm{C}_{60} \mathrm{H}_{21} \mathrm{~F}_{9}{ }^{-}$and (ii) $\mathrm{comparison}$ of arrival times of $\mathrm{C}_{60} \mathrm{H}_{21-x} \mathrm{~F}_{9-x}{ }^{-}(x=0-9)$ (HF loss, denoted by circles), $\mathrm{C}_{60} \mathrm{H}_{21-x-2 y} \mathrm{~F}_{9-x}{ }^{-}(y=0-5)$ (additional $\mathrm{H}_{2}$ loss, denoted by squares) and $\mathrm{C}_{60}$ (denoted by triangle) $)^{76}$. (Copyright ${ }^{\Theta} 2016$ American Chemical Society) b (i) Structures of polyoxometallate (POM) calibrants, Anderson $(R=$ tris (alkoxo) ligand (3) or aliphatic ligand (4), $\left.\left\{\mathrm{MnMo}_{6} \mathrm{O}_{24}\right\}\right)$, Keggin $\left(1,\left\{\mathrm{PW}_{12} \mathrm{O}_{40}\right\}\right)$, and Dawson $\left(2,\left\{\mathrm{P}_{2} \mathrm{~W}_{18} \mathrm{O}_{62}\right\}\right)$ clusters. (ii) ATDs obtained by using the POM clusters $\left(1=\right.$ green, $2=$ red, $3=$ orange, and $4=$ blue) as calibrants $^{77}$. (Copyright ${ }^{\oplus} 2016$ American Chemical Society)

schematic of the instrumental setup showing the formation of aggregates of the cluster under increased pressure conditions in the trap, and its subsequent separation in the IM chamber is presented in Fig. 6a. Chakraborty et al. have also shown that alkali metal ions can induce dimerization of $\left[\mathrm{Ag}_{29}(\mathrm{BDT})_{12}\right]^{3-} \mathrm{NCs}$ in a similar manner ${ }^{79}$. Baksi et al. identified isomerism in $\left[\mathrm{Ag}_{11}(\mathrm{SG})_{7}\right]^{-}$ cluster in the gas phase ${ }^{80}$. However, as the crystal structure of $\left[\mathrm{Ag}_{11}(\mathrm{SG})_{7}\right]^{-}$is not known, the correlation with the condensed-phase structures could not be established. In another report, the authors showed that $\left[\mathrm{Ag}_{44}(\mathrm{SR})_{30}\right]^{4-}$ and $\left[\mathrm{Ag}_{29}(\mathrm{BDT})_{12}\right]^{3-}$ clusters also show isomerism in the gas phase $\mathrm{e}^{81}$, which do not show any isomers in their crystal structure. Four distinct isomeric peaks were 


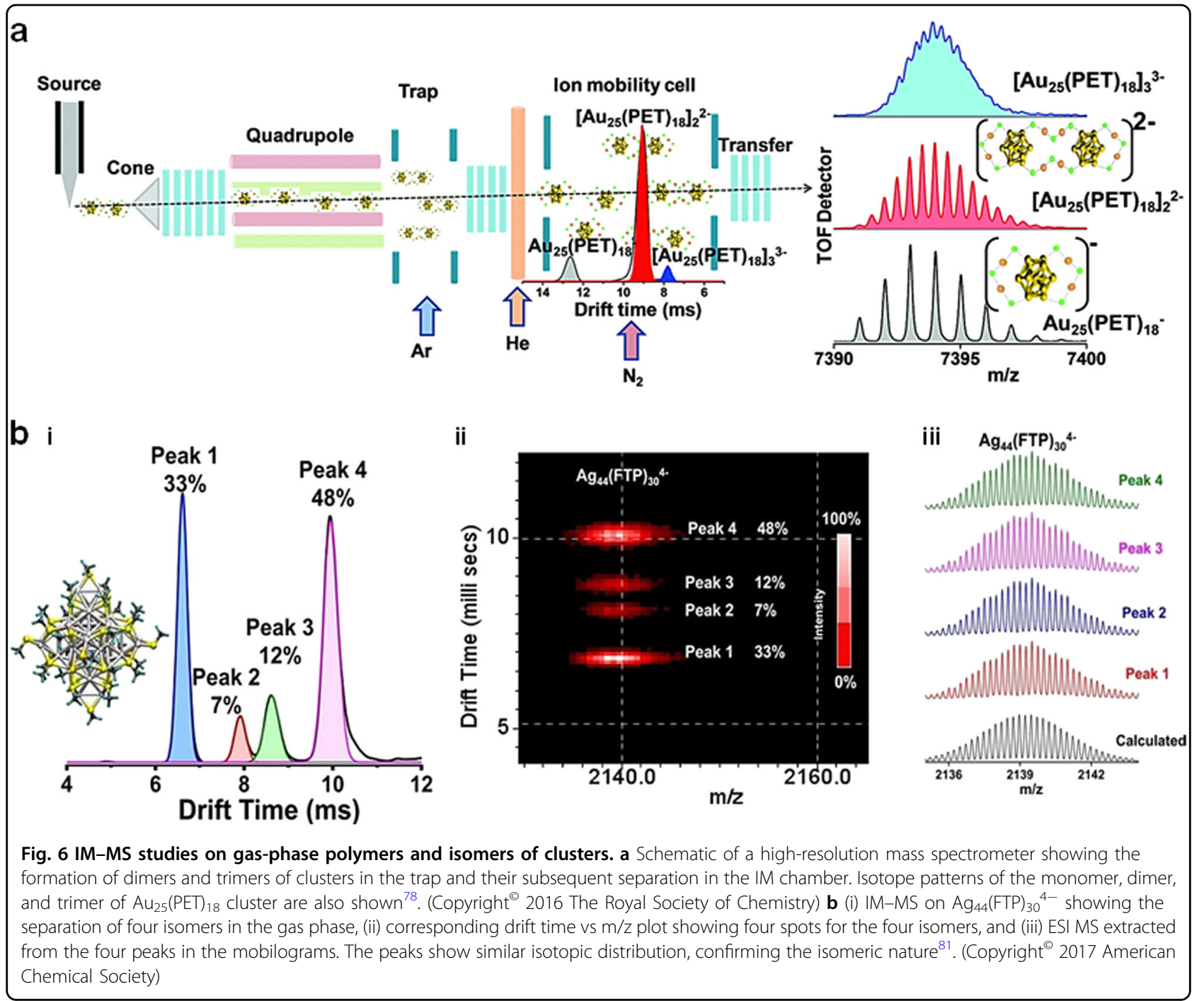

observed in IM-MS of $\left[\mathrm{Ag}_{44}(\mathrm{FTP})_{30}\right]^{4-}$ (Fig. 6b). However, two isomers were separated for $\left[\mathrm{Ag}_{44}(\mathrm{FTP})_{30}\right]^{3-}$, which indicated that isomerism is charge-state dependent. The influence of the ligand shell in isomerism was studied by using $\left[\mathrm{Ag}_{44}(\mathrm{SR})_{30}\right]$ clusters protected by different ligands, which showed different number of isomers. Also, $\mathrm{Au}_{25}(\mathrm{SR})_{18}$ and $\mathrm{Ag}_{25}(\mathrm{SR})_{18}$ clusters showed a single peak in IM, suggesting that isomerism is highly selective to the structure and the symmetry of the cluster.

Kappes et al. performed IM studies on Au cluster cations $\mathrm{Au}_{n}{ }^{+}$. Comparison of experimental CCS with that of theoretical CCS from DFT-optimized structures revealed that $\mathrm{Au}_{n}{ }^{+}$have planar structures for $n=3-7$, while for $n=8-10$, they show three-dimensional structures $^{82}$. In a recent study, Daly et al. characterized homometallic cluster ions, $\left[\mathrm{Ag}_{14}\left(\mathrm{C} \equiv \mathrm{C}^{\mathrm{t}} \mathrm{Bu}\right)_{12} \mathrm{Cl}\right]^{+}$, $\left[\mathrm{Ag}_{14}\left(\mathrm{C} \equiv \mathrm{C}^{\mathrm{t}} \mathrm{Bu}\right)_{12} \mathrm{Br}\right]^{+}$and heterometallic clusters ions, $\left[\mathrm{Ag}_{8} \mathrm{Cu}_{6}\left(\mathrm{C} \equiv \mathrm{C}^{\mathrm{t}} \mathrm{Bu}\right)_{12} \mathrm{Cl}\right]^{+}, \quad\left[\mathrm{Ag}_{8} \mathrm{Cu}_{6}\left(\mathrm{C} \equiv \mathrm{C}^{\mathrm{t}} \mathrm{Bu}\right)_{12} \mathrm{Br}\right]^{+}$by
$\mathrm{IM}-\mathrm{MS}^{83}$. These cluster ions showed a single peak in IM, and comparison of the CCS values derived from IM with the CCS values modeled from its X-ray crystal structure suggested that the gas-phase structures of the clusters resembled their condensed-phase structures (Fig. 7a, b). The shorter arrival time of the heterometallic cluster ions in comparison with that of the homometallic cluster ions was consistent with the observation from their crystal structures and DFT calculations (Fig. 7c). Thus, IM proved to be an effective tool not only for the separation of gas-phase entities but also for structural characterization of the clusters. In another study by Soleilhac et al., the size of GSH-protected clusters were compared in the solid, liquid, and gas phase by using X-ray powder diffraction (XRPD), time-resolved fluorescence anisotropy (TRFA), and IM-MS, respectively ${ }^{84}$. From the CCS values obtained from IM, the radii of the clusters were calculated as 1.22, 1.31, and $1.47 \mathrm{~nm}$ for $\mathrm{Au}_{15}(\mathrm{SG})_{13}, \mathrm{Au}_{18}(\mathrm{SG})_{14}$, and 
a

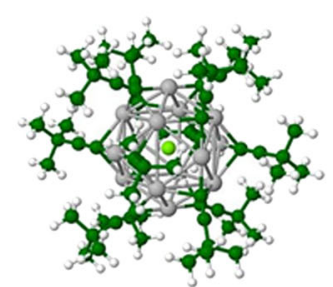

$\left[\mathrm{Ag}_{14}(\mathrm{C} \equiv \mathrm{CtBu})_{12} \mathrm{Cl}\right]^{+}$

$\left[\mathrm{Ag}_{8} \mathrm{Cu}_{6}(\mathrm{C} \equiv \mathrm{CtBu})_{12} \mathrm{Cl}\right]^{+}$

$\left[\mathrm{Ag}_{14}(\mathrm{C} \equiv \mathrm{CtBu})_{12} \mathrm{Br}\right]^{+}$

$\left[\mathrm{Ag}_{8} \mathrm{Cu}_{6}(\mathrm{C} \equiv \mathrm{C} t \mathrm{Bu})_{12} \mathrm{Br}\right]^{+}$

d
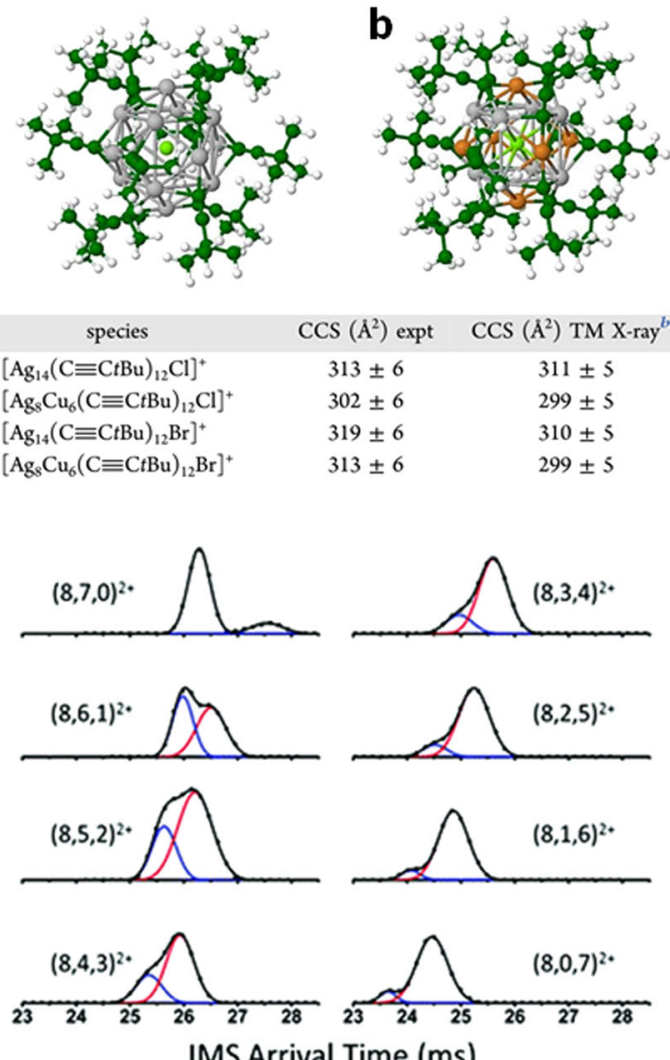

$\operatorname{CCS}\left(\AA^{2}\right) \operatorname{expt} \quad \operatorname{CCS}\left(\AA^{2}\right)$ TM X-ray ${ }^{b}$

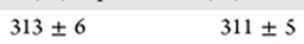

$302 \pm 6 \quad 299 \pm 5$

$319 \pm 6 \quad 310 \pm 5$

$313 \pm 6 \quad 299 \pm 5$

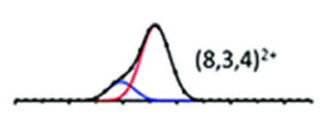

IMS Arrival Time (ms)

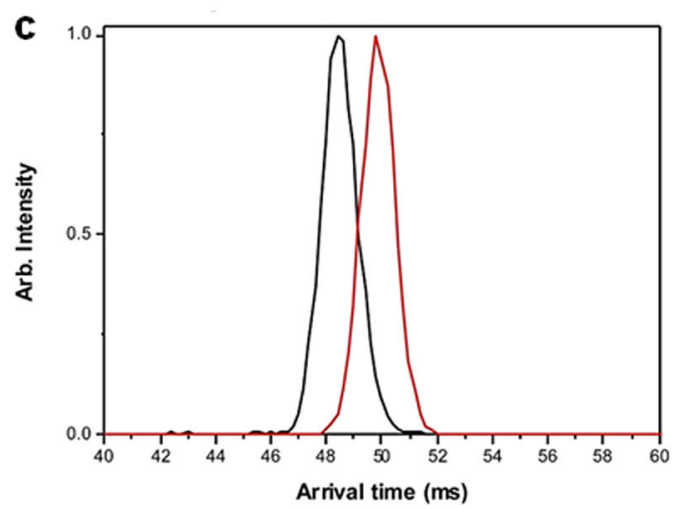

e

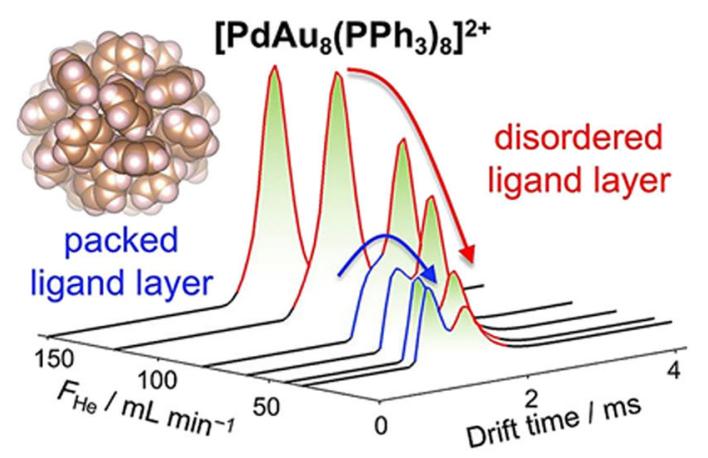

Fig. 7 IM-MS studies of gas-phase cluster ions. DFT-optimized structures of $\mathbf{a}\left[\mathrm{Ag}_{14}\left(\mathrm{C} \equiv \mathrm{C}^{\mathrm{t}} \mathrm{Bu}\right)_{12} \mathrm{Cl}\right]^{+}$and $\mathbf{b}\left[\mathrm{Ag}{ }_{8} \mathrm{Cu}{ }_{6}\left(\mathrm{C} \equiv \mathrm{C}^{\mathrm{t}} \mathrm{Bu}\right)_{12} \mathrm{Cl}\right]^{+}$. $\mathbf{c} \mathrm{IM}$ arrival times of $\left[\mathrm{Ag}_{14}\left(\mathrm{C} \equiv \mathrm{C}^{\mathrm{t}} \mathrm{Bu}\right)_{12} \mathrm{Cl}\right]^{+}$(red) and $\left[\mathrm{Ag}_{8} \mathrm{Cu} \mathrm{u}_{6}\left(\mathrm{C} \equiv \mathrm{C}^{\mathrm{t}} \mathrm{Bu}\right)_{12} \mathrm{Cl}\right]^{+}$(black) ${ }^{83}$. (Copyright ${ }^{\odot} 2017$ American Chemistry Society) $\mathbf{d}$ IM ATDs of

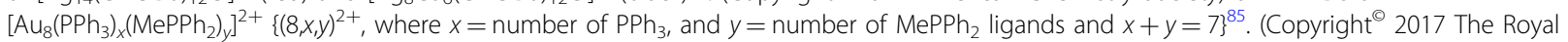
Society of Chemistry) e ATDs of $\left[\mathrm{PdAu}_{8}\left(\mathrm{PPh}_{3}\right)_{8}\right]^{2+}$ showing the interconversion of isomers as a function of $\mathrm{He} \mathrm{gas} \mathrm{flow}^{86}$. $\left(\mathrm{Copyright}^{\odot} 2018 \mathrm{American}^{\circ}\right.$ Chemical Society)

$\mathrm{Au}_{25}(\mathrm{SG})_{18}$, respectively. Though the absolute values differed, the trends in the size of the above NCs were similar in all the three phases. In comparison with techniques like XRPD and TRFA, IM-MS is expected to become a more convenient technique for determining the size of the clusters due to the ease of sample preparation and lower limit of error ( 2\%) compared with other techniques.

Ligare et al. used ESI IM-MS to study the structural changes upon systematic ligand exchange of $\left[\mathrm{Au}_{8}\left(\mathrm{PPh}_{3}\right)_{7}\right]^{2+}$ and $\left[\mathrm{Au}_{11}\left(\mathrm{PPh}_{3}\right)_{9} \mathrm{H}\right]^{2+}$ with methyldiphenylphosphine $\left(\mathrm{MePPh}_{2}\right)^{85}$. Studies revealed that $\left[\mathrm{Au}_{8}\left(\mathrm{PPh}_{3}\right)_{7}\right]^{2+}$ cluster showed two isomers, and on increasing ligand exchange with $\mathrm{MePPh}_{2}$, these isomers underwent a change in relative population from a more compact structure showing lower arrival time to a more extended structure showing larger arrival time, as shown in Fig. $7 d$. In contrast, $\left[\mathrm{Au}_{11}\left(\mathrm{PPh}_{3}\right)_{9} \mathrm{H}\right]^{2+}$ cluster showed only one isomer. Recently, Hirata et al. showed that phosphine-protected gold clusters like $\left[\mathrm{Au}_{9}\left(\mathrm{PPh}_{3}\right)_{8}\right]^{3+}$ and $\left[\mathrm{PdAu}_{8}\left(\mathrm{PPh}_{3}\right)_{8}\right]^{2+}$ undergo conversion to more compact isomers upon collisional excitation (Fig. 7e) ${ }^{86}$. Such studies help to understand the fluxionality in the structures of the NCs.

\section{Gas-phase dissociation studies of noble metal nanoclusters}

While IM-MS reveals enormous information regarding the shape, size, and conformations of the cluster ions, more information regarding their structure and bonding can be obtained from dissociation studies. In collisioninduced dissociation (CID), mass-selected ions are subjected to dissociation by collision with gases like $\mathrm{Ar}, \mathrm{N}_{2}$, $\mathrm{He}$, etc. Fields-Zinna et al. reported CID studies on ligand-protected $\mathrm{Au}_{25} \mathrm{NCs}$ and showed that the dissociation involved the $\mathrm{Au}_{2} \mathrm{~L}_{3}$ semirings, which are the staples motifs present in its crystal structure ${ }^{87}$. The authors used $\mathrm{Au}_{25}\left(\mathrm{SC}_{2} \mathrm{H}_{4} \mathrm{Ph}\right)_{18}$ cluster, and ligandexchanged it with $-\mathrm{S}\left(\mathrm{CH}_{2} \mathrm{CH}_{2} \mathrm{O}\right)_{5} \mathrm{CH}_{3}$ (-SPEG) to facilitate ionization and studied CID on these mixed ligandprotected $\mathrm{Na}_{x} \mathrm{Au}_{25}\left(\mathrm{SC}_{2} \mathrm{H}_{4} \mathrm{Ph}\right)_{18-y}\left(\mathrm{~S}_{(}\left(\mathrm{C}_{2} \mathrm{H}_{4} \mathrm{O}\right)_{5} \mathrm{CH}_{3}\right)_{y}$ clusters using ESI TOF and ESI FTICR MS. CID produced 


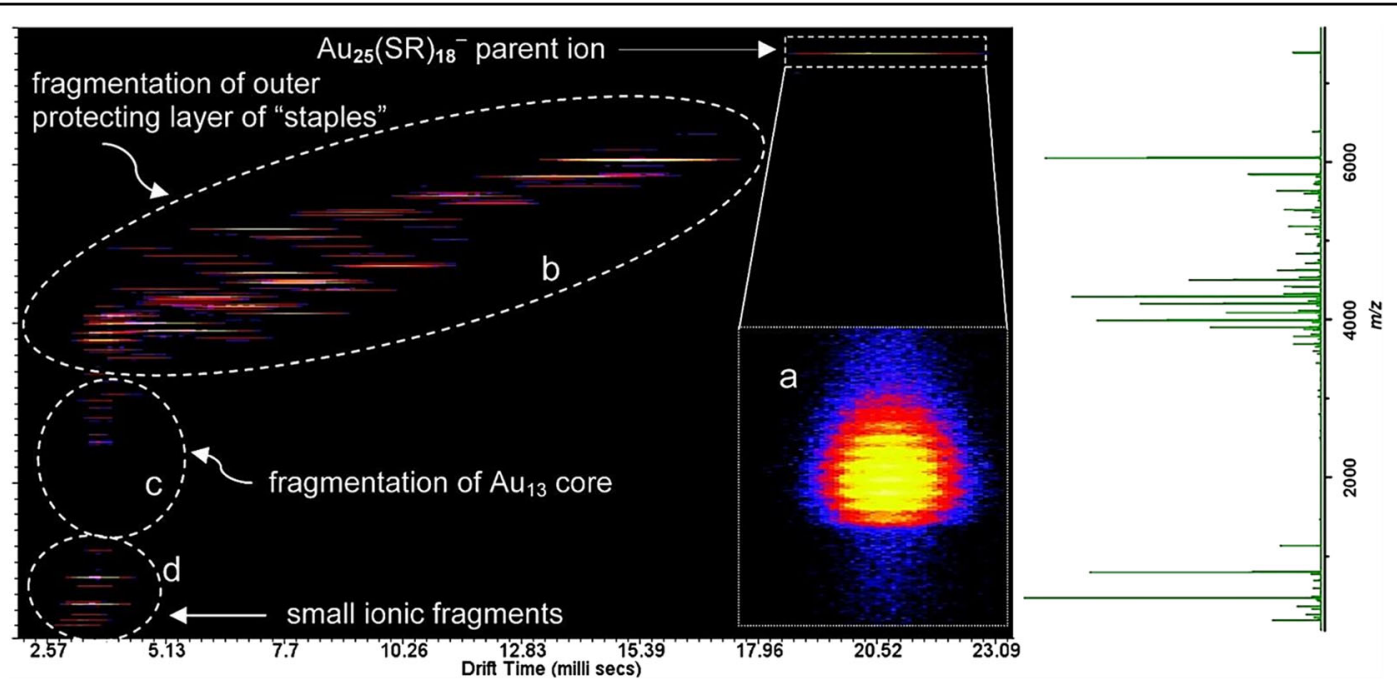

Fig. 8 IM-MS/MS of $\mathbf{A u}_{\mathbf{2 5}}(\mathrm{PET})_{18}{ }^{-}$. Plot of $\mathrm{m} / \mathrm{z}$ vs drift time showing the analysis of the fragments. Insets, a isotopic distribution of parent $\mathrm{Au}_{25}(\mathrm{PET})_{18}{ }^{-}$, b ions produced by fragmentation of outer staple, $\mathbf{c}$ fragmentation of $\mathrm{Au}_{13}(\mathrm{SR})_{\mathrm{m}}(\mathrm{S})_{n}$ core, and $\mathbf{d}$ smaller ionic fragments ${ }^{88}$. (Copyright ${ }^{\odot}$ 2010 American Chemical Society)

fragments such as $\left[\mathrm{Na}_{2} \mathrm{Au}_{2} \mathrm{~L}_{3}\right]^{1+}$ representing the loss of a single semiring and fragments such as $\left[\mathrm{NaAu}_{3} \mathrm{~L}_{3}\right]^{1+}$ and $\left[\mathrm{NaAu}_{4} \mathrm{~L}_{4}\right]^{1+}$ representing the loss of multiple semirings ${ }^{87}$. Later, Angel et al. studied the fragmentation of $\mathrm{Au}_{25} \mathrm{~L}_{18}{ }^{-} \mathrm{NCs}$ using HR ESI MS ${ }^{88}$. The predominant fragmentation pathway involved the loss of $\mathrm{Au}_{4} \mathrm{~L}_{4}$ leading to the formation of fragment ions, such as $\mathrm{Au}_{21} \mathrm{~L}_{14}{ }^{-}$and $\mathrm{Au}_{17} \mathrm{~L}_{10}{ }^{-}$. They also introduced the use of IM-MS/MS, a technique where IM is coupled to CID, which could differentiate between fragmentation from the outer staples, fragmentation from the icosahedral core and the smaller ionic fragments, by separating them into distinct bands (Fig. 8). Black et al. carried out CID on larger Au NCs like $\mathrm{Au}_{144}(\mathrm{SR})_{60}$ and $\mathrm{Au}_{130}(\mathrm{SR})_{50}$, and also showed that the extent of fragmentation is specific to the charge state of the cluster ions ${ }^{89}$. CID of mixed-ligand-protected cluster, $\left[\mathrm{Au}_{11}\left(\mathrm{PPh}_{3}\right)_{8} \mathrm{X}_{2}\right]^{+}(\mathrm{X}=\mathrm{Cl}, \mathrm{C} \equiv \mathrm{CPh})$, showed competing fragmentation channels involving sequential loss of $\mathrm{PPh}_{3}$ and $\mathrm{Au}_{\mathrm{X}}\left(\mathrm{PPh}_{3}\right)^{90}$.

The extent of fragmentation also depends on the internal energy distribution of the ions, and hence CID studies were used to understand the stabilities of the cluster ions. Taking $\mathrm{Ag}_{29}(\mathrm{SR})_{12}, \quad \mathrm{Ag}_{25}(\mathrm{SR})_{18}$, and $\mathrm{Ag}_{44}(\mathrm{SR})_{30} \mathrm{NCs}$ as examples, Chakraborty et al. demonstrated that the predominant fragmentation pathways of these $\mathrm{NCs}$ involved the loss of $\mathrm{Ag}_{5}(\mathrm{SR})_{6}{ }^{-}, \mathrm{Ag}(\mathrm{SR})^{-}$, or $\mathrm{Ag}_{2}(\mathrm{SR})_{3}{ }^{-}$fragments ${ }^{91}$. By using survival yield analysis and comparing the values of $\mathrm{E}_{\mathrm{com} 50}\left(\mathrm{E}_{\mathrm{com50}}\right.$ is center-ofmass energy corresponding to $50 \%$ dissociation of the cluster), the stabilities of these clusters were compared (Fig. $9 \mathrm{a})$, and the order of gas-phase stability $\left[\mathrm{Ag}_{29}(\mathrm{SR})_{12}\right]^{3-}$ $>\left[\mathrm{Ag}_{25}(\mathrm{SR})_{18}\right]^{-}>\left[\mathrm{Ag}_{44}(\mathrm{SR})_{30}\right]^{3-}$ was similar to that observed in the solution phase.
Another technique that can be effectively used to study the energetics and kinetics of the fragmentation process is surface-induced dissociation (SID). In this process, massselected ions are collided with a surface (usually Au surfaces protected by monolayers of alkanethiols) and impact induced activation leads to dissociation. In comparison with CID, SID is a more convenient technique to extract thermodynamic parameters of the cluster ions, as here the applied CE can be varied through a large range to observe a small change in the threshold internal energies of large ions. Using SID, Johnson et al. quantified the stability and ligand-binding energies of small TPP-protected Au clusters, $\mathrm{Au}_{7} \mathrm{~L}_{6}{ }^{2+}, \mathrm{Au}_{8} \mathrm{~L}_{6}{ }^{2+}, \mathrm{Au}_{8} \mathrm{~L}_{7}{ }^{2+}$, and $\mathrm{Au}_{9} \mathrm{~L}_{7}{ }^{2+92}$. Collision energy-resolved fragmentation curves revealed that $\mathrm{Au}_{8} \mathrm{~L}_{6}{ }^{2+}$ cluster was more stable toward dissociation (Fig. 9bi). SID enabled the quantitative estimation of the threshold energies and activation entropies of fragmentation. It also enabled to understand the kinetics of fragmentation by determining the microcanonical rate constants for the different fragmentation pathways (Fig. 9bii) and hence determining the kinetically and thermodynamically favored pathways. Moreover, taking $\mathrm{Ag}_{11}(\mathrm{SG})^{7-}$ clusters as an example, Baksi et al. showed that CID and SID of the clusters occurred through different pathways. SID produced more fragments compared with CID, and charge stripping from 3- to 2- and 1charge states of the cluster ions occurred ${ }^{80}$.

While both CID and SID produces a lesser number of fragments, extensive fragmentation can be observed by ultraviolet photodissociation (UVPD) as observed in the case of $\mathrm{Au}_{25}(p \mathrm{MBA})_{18}$ and $\mathrm{Au}_{36}(p \mathrm{MBA})_{24} \mathrm{NCs}^{93}$. UVPD on these clusters using $\lambda=193 \mathrm{~nm}$ involved high-energy fragmentation pathways and cleavage of $\mathrm{Au}-\mathrm{S}$ and $\mathrm{C}-\mathrm{S}$ 

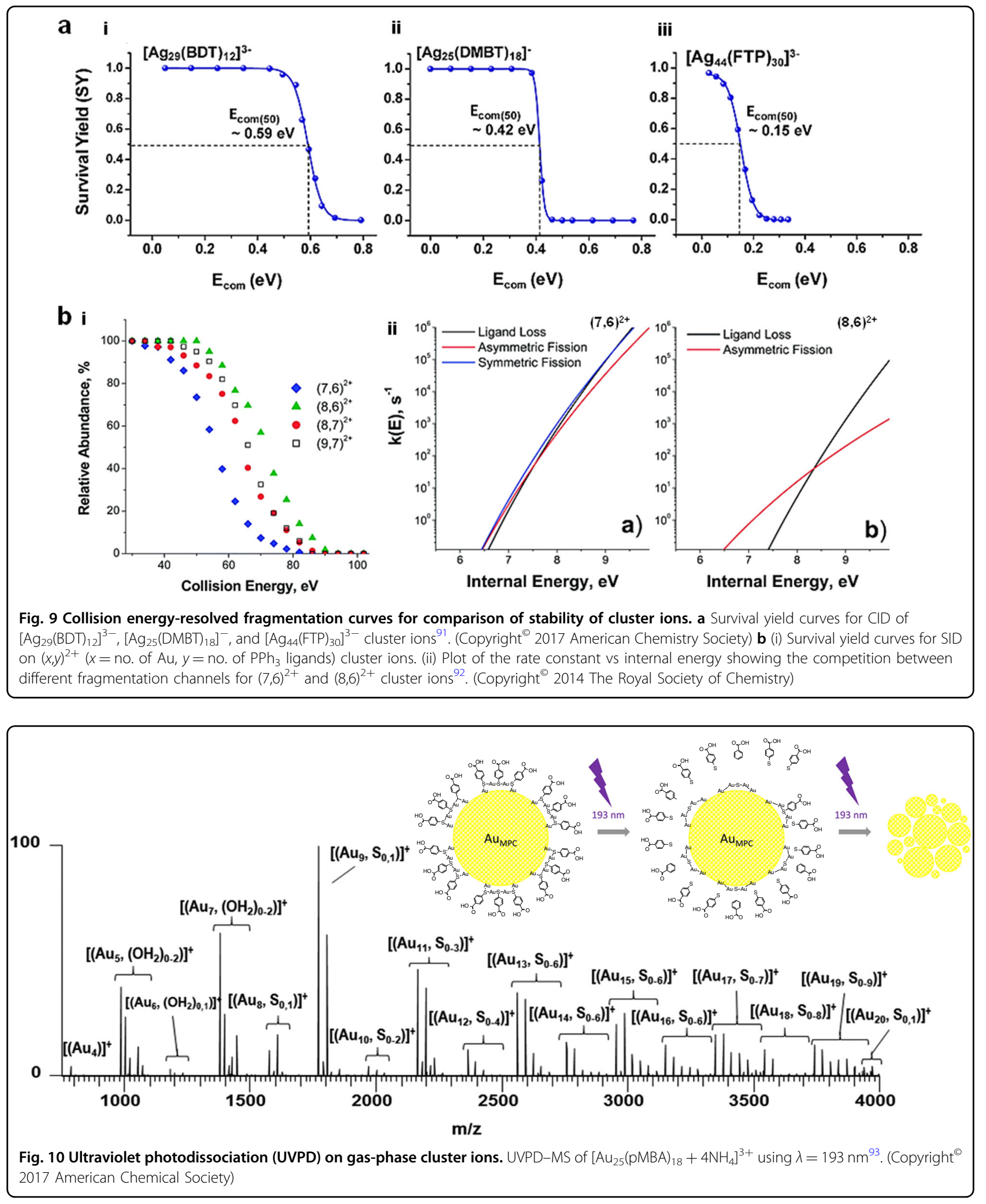

bonds. When the cluster ions were exposed to multiple laser pulses, a series of bare Au cluster ions were formed by sequential evaporation of neutral $\mathrm{Au}$ atoms (Fig. 10).
Recently, Ghosh et al. showed that the bare cluster ion, $\mathrm{Ag}_{17}{ }^{+}$, can be produced selectively by CID of $\left[\mathrm{Ag}_{18}(\mathrm{TPP})_{10} \mathrm{H}_{16}\right]^{2+}$ clusters and by further increasing the 


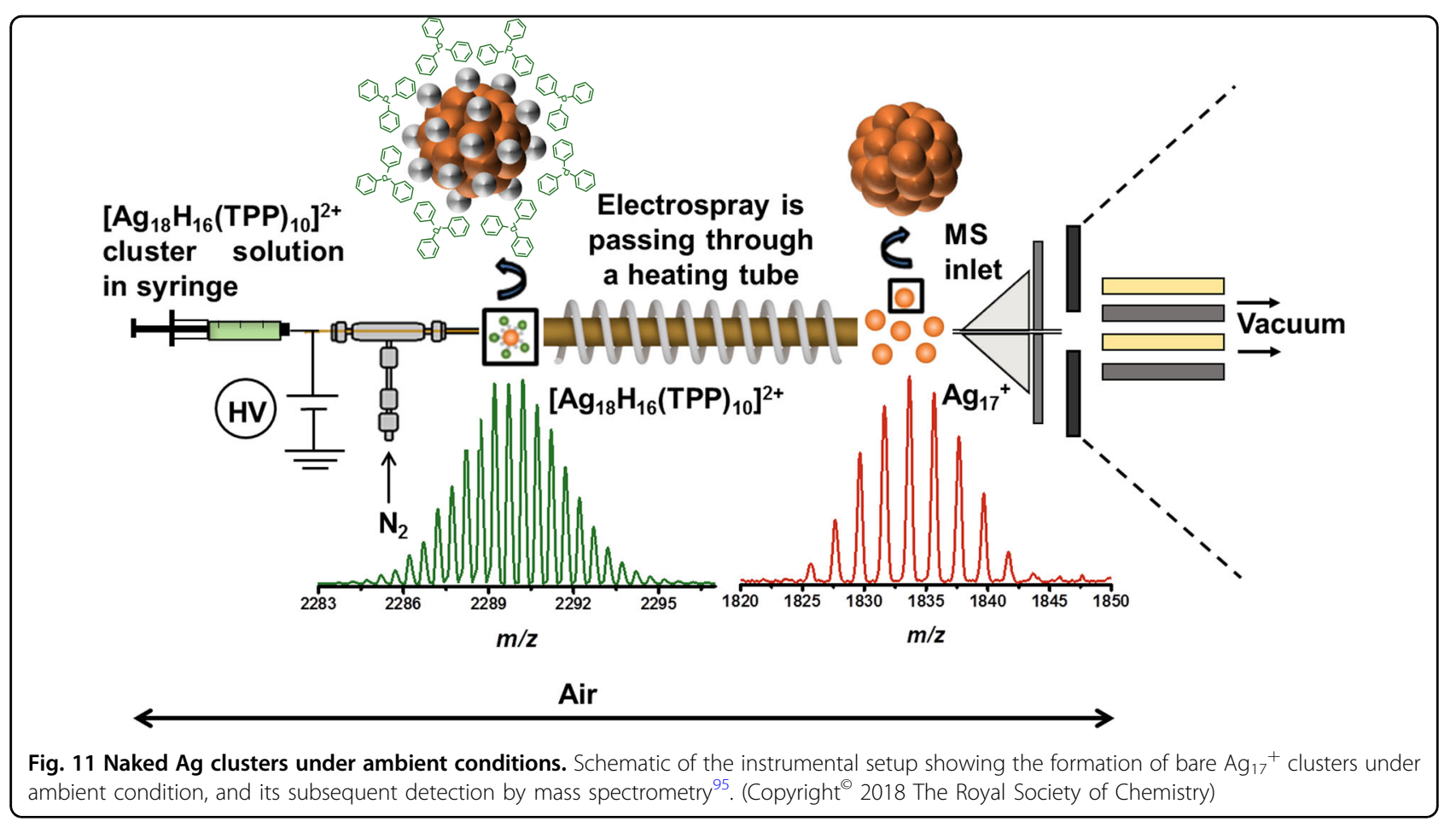

collision energy, a series of $\mathrm{Ag}_{\mathrm{n}}{ }^{+}(n=1-17)$ clusters may be produced ${ }^{63,94}$. In a similar manner, $\left[\mathrm{Ag}_{25}(\mathrm{DPPE})_{8} \mathrm{H}_{22}\right]^{3+}$ and $\left[\mathrm{Ag}_{22}(\mathrm{DPPE})_{8} \mathrm{H}_{19}\right]^{3+}$ were also used as precursors for bare $\mathrm{Ag}$ clusters ${ }^{94}$. In a recent study by Jash et al., electrosprayed $\left[\mathrm{Ag}_{18}(\mathrm{TPP})_{10} \mathrm{H}_{16}\right]^{2+}$ clusters were passed through a heated tube, whereby all the ligand layers were desorbed leading to the formation of $\mathrm{Ag}_{17}{ }^{+}$under ambient conditions, and the product ions were subsequently detected by MS (Fig. 11) ${ }^{95}$.

\section{Spectroscopy on the mass-selected gas-phase cluster ions}

The electronic properties of the NCs are probed experimentally by optical and electrochemical studies in solution. However, these experimental results are influenced by the solvents and the counter ions present in solution. So, there is a need to directly probe the energy levels of the isolated cluster ions in vacuum. Anion PES is usually used to determine HOMO-LUMO gaps and EAs. Such studies have been done for bare $\mathrm{Au}_{n}{ }^{-}$clusters $^{96}$. Recently, Hirata et al. performed PES on isolated $\left[\mathrm{Au}_{25}\left(\mathrm{SC}_{12} \mathrm{H}_{25}\right)_{18}\right]^{-}$ions by coupling a magnetic bottletype photoelectron spectrometer with a TOF mass spectrometer ${ }^{97}$. Schematic of the instrumental setup used for the study is presented in Fig. 12a. The photoelectron spectrum of $\left[\mathrm{Au}_{25}\left(\mathrm{SC}_{12} \mathrm{H}_{25}\right)_{18}\right]^{-}$showed two bands, A and B (Fig. 12b), corresponding to electron detachment from $1 \mathrm{P}$ superatomic and Au $5 \mathrm{~d}$ orbitals localized on the core Au atoms. The vertical detachment energy (VDE) and adiabatic electron affinity (AEA) of $\left[\mathrm{Au}_{25}\left(\mathrm{SC}_{12} \mathrm{H}_{25}\right)_{18}\right]$ was determined to be $2.5 \mathrm{eV}$ and $2.2 \mathrm{eV}$, which corresponds to the values of $E_{\mathrm{top}}$ and $E_{\mathrm{th}}$ in the photoelectron spectrum (Fig. 12b), respectively. Hamouda et al. studied photoexcitation of $\left[\mathrm{Au}_{25}(\mathrm{SG})_{18^{-}}\right.$ $6 \mathrm{H}]^{7-}$, where the yield of electron detachment as a function of the laser wavelength gave the gas-phase optical action spectra, which was found to be similar to the solution-phase spectrum ${ }^{98}$. Daly et al. studied the photofragmentation and VUV photoionization of $\left[\mathrm{Ag}_{10} \mathrm{D}_{8} \mathrm{~L}_{6}\right]^{2+} \mathrm{NCs}$ in the gas phase by coupling a linear ion trap mass spectrometer with a beamline of synchrotron, capable of producing high flux of photons that could be tuned in the entire VUV range ${ }^{99}$. Upon photoexcitation of $\left[\mathrm{Ag}_{10} \mathrm{D}_{8} \mathrm{~L}_{6}\right]^{2+}$, a number of photofragments were produced, such as $\left[\mathrm{Ag}_{10} \mathrm{D}_{8} \mathrm{~L}_{6}\right]^{3+}$, $\left[\mathrm{Ag}_{10} \mathrm{D}_{8} \mathrm{~L}_{5}\right]^{2+},\left[\mathrm{Ag}_{10} \mathrm{D}_{8} \mathrm{~L}_{4}\right]^{2+},\left[\mathrm{Ag}_{9} \mathrm{D}_{8} \mathrm{~L}_{4}\right]^{2+}$, and $\left[\mathrm{AgL}_{2}\right]^{+}$. The ionization onset of $\left[\mathrm{Ag}_{10} \mathrm{D}_{8} \mathrm{~L}_{6}\right]^{2+}$ was determined from the onsets in the yield of $\left[\mathrm{Ag}_{10} \mathrm{D}_{8} \mathrm{~L}_{6}\right]^{3+}$ as a function of photon energy. Two ionization onsets were determined as $\sim 9.3 \mathrm{eV}$ and $\sim 10.6 \mathrm{eV}$, which might be due to removal of electrons from orbitals of different energy levels. In another study, authors from the same group performed VUV and UV spectroscopy on $\left[\mathrm{Ag}_{14}\right.$ $\left.{ }_{n} \mathrm{Cu}_{n}(\mathrm{C} \equiv \mathrm{CtBu})_{12} \mathrm{X}\right]^{+}(\mathrm{X}=\mathrm{Cl}$ and $\mathrm{Br})$ cluster ions ${ }^{83}$. The ionization onsets of the cluster ions were determined to be $\sim 8.8 \mathrm{eV}$, and this was similar for all the ions, irrespective of the nature of halides or the extent of $\mathrm{Cu}$ doping (Fig. 12c). Photofragmentation of the same 

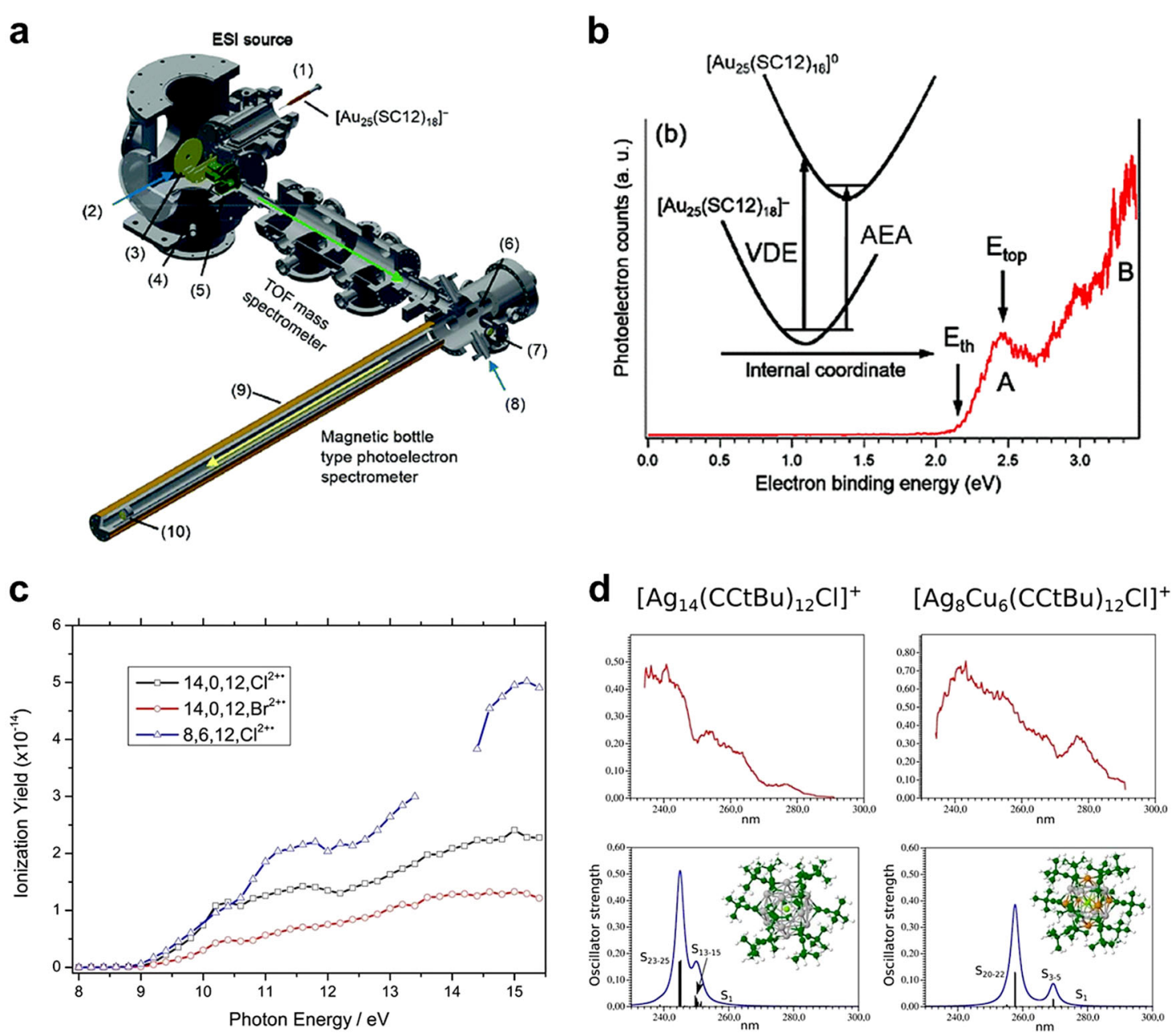

Fig. 12 Spectroscopy on gas-phase cluster ions. a Schematic of the instrumental setup showing the coupling of a magnetic bottle-type photoelectron spectrometer with a TOF mass spectrometer. (1) Syringe, (2) photodissociation laser, (3) acceleration grids, (4) deflectors, (5) einzel lens, (6) permanent magnet, (7) microsphere plate, (8) photodetachment laser, (9) coil, and (10) microchannel plate. b Photoelectron spectrum of $\left[\mathrm{Au}_{25}\left(\mathrm{SC}_{12}\right)_{18}\right]^{-}$at $355 \mathrm{~nm}$. Inset shows a schematic of the potential energy curves of the cluster ions ${ }^{97}$. (Copyright ${ }^{\circ} 2017$ The Royal Society of Chemistry) c Plot of ionization yield vs VUV energy of $\left[\mathrm{Ag}_{14}\left(\mathrm{C} \equiv \mathrm{C}^{\mathrm{t} B u}\right)_{12} \mathrm{Cl}\right]^{+},\left[\mathrm{Ag}_{8} \mathrm{Cu} \mathrm{u}_{6}\left(\mathrm{C} \equiv \mathrm{C}^{\mathrm{t} B u}\right)_{12} \mathrm{Cl}\right]^{+}$, and $\left[\mathrm{Ag}_{14}\left(\mathrm{C} \equiv \mathrm{C}^{\mathrm{t}} \mathrm{Bu}\right)_{12} \mathrm{Br}\right]^{+}$cluster ions showing their onsets of ionization. The yield of the product ions as a function of the photon energy is shown for $\left[\mathrm{Ag}_{14}\left(\mathrm{C} \equiv \mathrm{C}^{\mathrm{t}} \mathrm{Bu}\right)_{12} \mathrm{Cl}\right]^{2+},\left[\mathrm{Ag}{ }_{8} \mathrm{Cu} \mathrm{u}_{6}\left(\mathrm{C} \equiv \mathrm{C}^{\mathrm{t}} \mathrm{Bu}\right)_{12} \mathrm{Cl}\right]^{2+}$, and $\left[\mathrm{Ag}_{14}\left(\mathrm{C} \equiv \mathrm{C}^{\mathrm{t} B u}\right)_{12} \mathrm{Br}\right]^{2+}$. $\mathbf{d}$ Gas-phase UV spectra of $\left[\mathrm{Ag}_{14}\left(\mathrm{CC} \mathrm{Bu}^{\mathrm{B}}\right)_{12} \mathrm{Cl}\right]^{+}$and $\left[\mathrm{Ag}_{8} \mathrm{Cu}_{6}\left(\mathrm{CC} \mathrm{CBu}_{12} \mathrm{Cl}\right)\right]^{+}$cluster ions. The TDDFT spectra are also presented, which shows similar trends in the shifts for $\mathrm{Ag}_{14}$ and $\mathrm{Ag}_{8} \mathrm{Cu}_{6}$ Cluster ions ${ }^{83}$. (Copyright ${ }^{\circ} 2017$ American Chemical Society)

clusters were studied in the wavelength range of $235-291 \mathrm{~nm}$ by coupling a laser with the ion trap. The plot of photofragmentation yield as a function of the wavelength of the radiation gave the UV spectra of the cluster ions in the gas phase (Fig. 12d). The experimental optical absorption spectra were also in accordance with TDDFT calculations (Fig. 12d).

\section{Resolving the solution-phase growth and nucleation of clusters}

Apart from such studies on gas-phase cluster ions, MS also proved to be powerful in unrevealing complex solution-phase phenomena. Understanding the mechanism of nucleation and growth of clusters in solution has always remained challenging. In 2012, Yu et al. reported the size controlled growth of $\mathrm{Au}_{25} \mathrm{NCs}$ where they slowed down the reduction rate by using $\mathrm{CO}$ as a mild reducing agent ${ }^{100}$. By using MALDI MS, the authors demonstrated that a mixture of $\mathrm{Au}_{10-15} \mathrm{NCs}$ was produced within $5 \mathrm{~min}$ of reaction, followed by the formation of $\mathrm{Au}_{16-25} \mathrm{NCs}$ over a period of $40 \mathrm{~min}$, which finally size focussed to $\mathrm{Au}_{25} \mathrm{NCs}$ after $24 \mathrm{~h}$. However, due to fragmentation, only the core masses could be identified, and no information was obtained about the ligand shell of the intermediate 
products. More recently, in 2014, in another report from the same group, ESI MS was used to trace all the stable intermediates involved in the formation of $\mathrm{Au}_{25}$ clusters starting from $\mathrm{Au}$ thiolates. This study showed that the formation of $\mathrm{Au} \mathrm{NCs}$ occurred by a 2e hopping process, which involved a fast reduction step followed by slow interconversion and size focussing steps ${ }^{101}$. All the intermediates involved in the process were detected by ESI MS, and the changes in the solution composition with gradual growth of the NCs were also in accordance with the changes in the optical absorption features (Fig. 13). Similar studies have been reported by the same group where ESI MS was used to understand the steps involved in the process of conversion of $\mathrm{Au}_{25}$ to $\mathrm{Au}_{44} \mathrm{NCs}^{102}$. Isoelectronic conversion from $\left[\mathrm{Au}_{23}(\mathrm{SR})_{16}\right]^{-}$to $\left[\mathrm{Au}_{25}(\mathrm{SR})_{18}\right]^{-} \mathrm{NCs}$ was also studied by ESI MS. Careful mass spectrometric analysis of the system revealed the size-conversion reaction as $\left[\mathrm{Au}_{23}(\mathrm{SR})_{16}\right]^{-}+2$ $\left[\mathrm{Au}_{2}(\mathrm{SR})_{3}\right]^{-} \rightarrow\left[\mathrm{Au}_{25}(\mathrm{SR})_{18}\right]^{-}+2\left[\mathrm{Au}(\mathrm{SR})_{2}\right]^{-103}$. Based on HRMS measurements, Chen et al. have recently formulated a balanced equation for the stoichiometric synthesis of $\mathrm{Au}_{25}(\mathrm{SR})_{18} \mathrm{NCs}$ as, $32 / \mathrm{x}[\mathrm{Au}(\mathrm{SR})]_{\mathrm{x}}+8 \mathrm{e}-=$ $\left[\mathrm{Au}_{25}(\mathrm{SR})_{18}\right]^{-}+7\left[\mathrm{Au}(\mathrm{SR})_{2}\right]^{-104}$. Similar studies have also been done to understand the growth of silver clusters like $\left[\mathrm{Ag}_{17}\left(\mathrm{SPh}-{ }^{\mathrm{t}} \mathrm{Bu}\right)_{12}\right]^{3-}$ and $\left[\mathrm{Ag}_{44}\left(\mathrm{SPh}-{ }^{\mathrm{t}} \mathrm{Bu}\right)_{30}\right]^{4-105}$, and step-by-step mechanism of ligand exchange induced cluster conversion reactions, e.g., the conversion from $\mathrm{Ag}_{44}$ to $\mathrm{Ag}_{25}$ clusters and vice versa ${ }^{106}$.

\section{Reactions between nanoparticles}

Inter-cluster reactions are an emerging area in the field of $\mathrm{NCs}^{107}$. Krishnadas et al. demonstrated the reaction between $\mathrm{Au}_{25}(\mathrm{FTP})_{18}$ and $\mathrm{Ag}_{44}(\mathrm{FTP})_{30} \mathrm{NCs}$, which produces a mixture of alloy clusters in solution ${ }^{108,109}$. Exchange of $\mathrm{Au}-\mathrm{Ag}$ atoms between the clusters were observed by using MALDI and ESI MS (Fig. 14a, b). In case of reaction between clusters protected by different ligands like $\mathrm{Au}_{25}(\mathrm{PET})_{18}$ and $\mathrm{Ag}_{44}(\mathrm{FTP})_{30}$, ligand exchanges were also observed in MS. In another report from the same group, the authors demonstrated reaction between $\mathrm{Au}_{25}(\mathrm{SR})_{18}$ and $\mathrm{Ag}_{25}(\mathrm{SR})_{18}$ clusters leading to the formation of alloy clusters $\mathrm{Ag}_{\mathrm{m}} \mathrm{Au}_{\mathrm{n}}(\mathrm{SR})_{18}(n=1-24)$ (Fig. $14 \mathrm{c})^{110}$. The authors also detected a dianionic intermediate, $\left[\mathrm{Ag}_{25} \mathrm{Au}_{25}(\mathrm{SR})_{36}\right]^{2-}$ (Fig. 14d) at the early stages of the reaction, which provided better insights into the mechanism of such reactions. Salassa et al. used MALDI MS and NMR spectroscopy to show that monolayers of clusters are dynamic in nature, and inter-cluster ligand exchanges can occur during collision between the $\mathrm{NCs}^{111}$. Using isotopically pure silver clusters made of ${ }^{107} \mathrm{Ag}$ and ${ }^{109} \mathrm{Ag}$, Chakraborty et al. studied rapid isotopic exchange in silver clusters by HR ESI MS and found that the solution-state exchange dynamics of the clusters is similar to that occurring in water $\left(\mathrm{H}_{2} \mathrm{O}+\mathrm{D}_{2} \mathrm{O}=2 \mathrm{HDO}\right)^{112}$.

\section{Supramolecular chemistry of monolayer- protected noble metal NCs}

MS has also been used for exploring supramolecular chemistry of clusters. Chakraborty et al. studied supramolecular functionalization of $\left[\mathrm{Ag}_{29}(\mathrm{BDT})_{12}\right]^{3-}$ clusters with fullerenes $\left(C_{60}\right.$ and $\left.C_{70}\right)$ by HR ESI MS (Fig. 15a) ${ }^{113}$. The authors also used CID studies to gain further insights into the nature of the interaction and IM-MS (Fig. 15b) to study the structure of the adducts. Mathew et al. studied supramolecular functionalization of $\left[\mathrm{Au}_{25}(\mathrm{SBB})_{18}\right]^{-}$clusters with cyclodextrins $(\mathrm{CD})$, the adducts $\left[\mathrm{Au}_{25}(\mathrm{SBB})_{18} \cap\right.$ $\left.\mathrm{CD}_{n}\right]^{-}(n=1-4)$ were characterized by using MALDI and ESI MS (Fig. 15c) ${ }^{114}$. Recently, Nag et al. separated isomers of the inclusion complexes $\left[\mathrm{Ag}_{29}(\mathrm{BDT})_{12} \cap \mathrm{CD}_{n}\right]^{3-}$ $(n=1-6)$ (Fig. $15 \mathrm{~d}$ ) by using IM-MS ${ }^{115}$. Two isomers were observed for $n=2,3$, and 4 while no isomerism was observed in the case of $n=1,5$, and 6 complexes, suggesting similar behavior to that observed in octahedral transition metal co-ordination complexes.

\section{Liquid chromatography (LC) -MS}

Characterization, analysis, and separation of mixtures of clusters by chromatography have been pursued for long ${ }^{116}$. Some of the recent developments include directly coupling chromatographic techniques to MS. Black et al. coupled reversed-phase chromatography with mass spectrometry and separated gold clusters of varying core sizes from their mixtures ${ }^{117}$. The same group also coupled capillary LC to ESI and separated $A u_{104} \mathrm{~L}_{45}, \mathrm{Au}_{130} \mathrm{~L}_{50}, \mathrm{Au}_{137} \mathrm{~L}_{56}$, and $\mathrm{Au}_{144} \mathrm{~L}_{60}$ clusters from their mixtures (Fig. 16a) ${ }^{118}$. In another report, isomers of $\mathrm{Ag}_{29}(\mathrm{LA})_{12}(\mathrm{LA}=(\mathrm{R})-\alpha$ lipoic acid) clusters were separated using LC-MS (Fig. 16b) ${ }^{119}$.

\section{Toward nanoparticles}

Though the atomically precise NCs have been extensively characterized by MS, plasmonic NPs are not atomically precise, and determination of their exact composition still remains challenging. Recently, with the tremendous advancement in instrumentation and using a combination of ESI, LDI, and MALDI MS, it has been possible to assign approximate composition to some such plasmonic NPs, e.g., $\mathrm{Au}_{333}(\mathrm{SR})_{39}{ }^{53}, \mathrm{Au}_{\sim 500}(\mathrm{SR})_{\sim 120}{ }^{120}$, $\mathrm{Au}_{\sim 940}(\mathrm{SR})_{\sim 160}{ }^{121}$, etc. NPs. Recently in 2017, the crystal structure of a plasmonic $\mathrm{NP}, \mathrm{Au}_{279}\left(\mathrm{SPh}-{ }^{\mathrm{t}} \mathrm{Bu}\right)_{84}$ was reported $^{122}$. MS measurements also revealed the composition in accordance with the crystal structure. Even larger NPs, $\mathrm{Au}_{\sim 1400}{ }^{123}$ with a mass of $\sim 300 \mathrm{kDa}$ (Fig. 17a) and $\mathrm{Au}_{\sim 2000}{ }^{124}$ with a mass of $\sim 400 \mathrm{kDa}$ (Fig. 17b) were recently characterized by MALDI MS.

\section{Mass spectrometry as a tool for materials synthesis}

Electrospray as a method of ionization has also been used for organic synthesis ${ }^{125,126}$. While synthesis of new molecules 
a

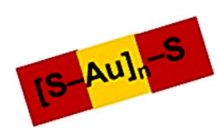

$\mathrm{Au}(\mathrm{I})-\mathrm{SR}$

Complex (0 e-)

b

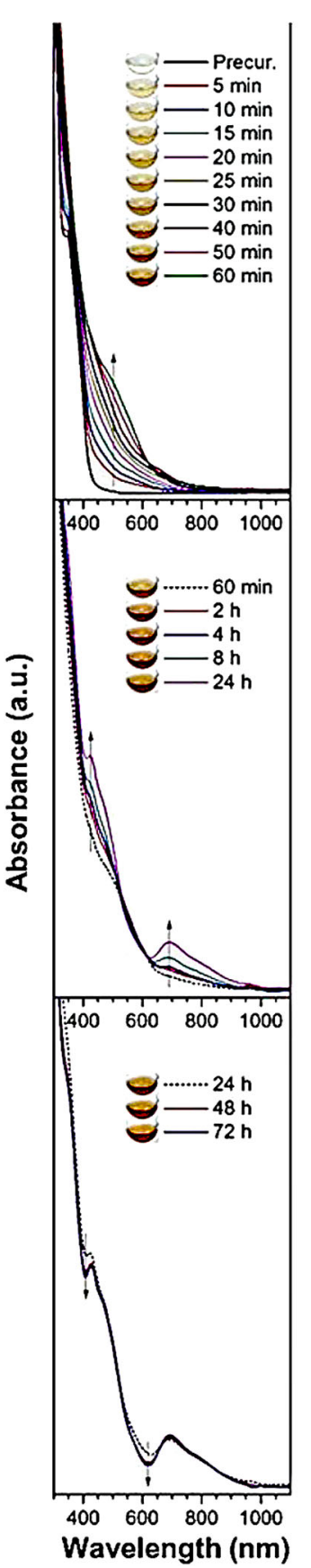

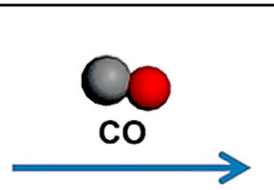
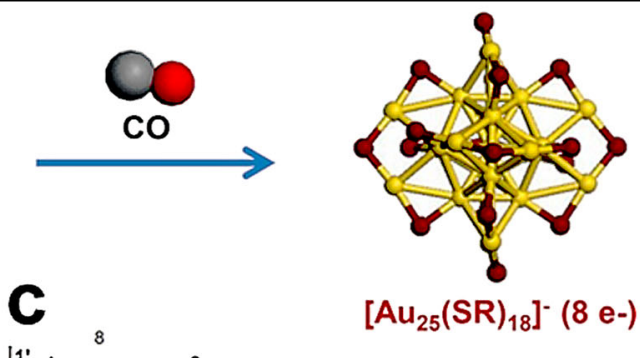

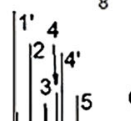

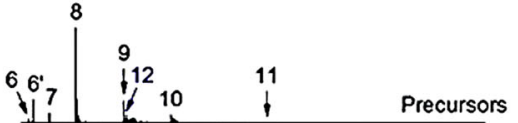

Inlel

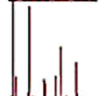

1.
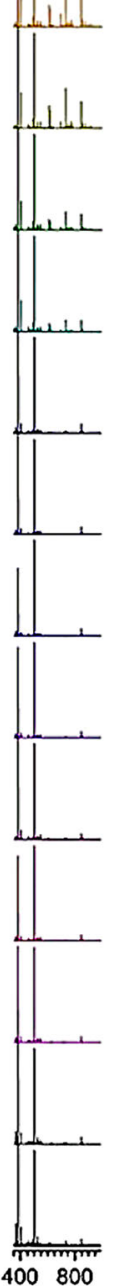

400800
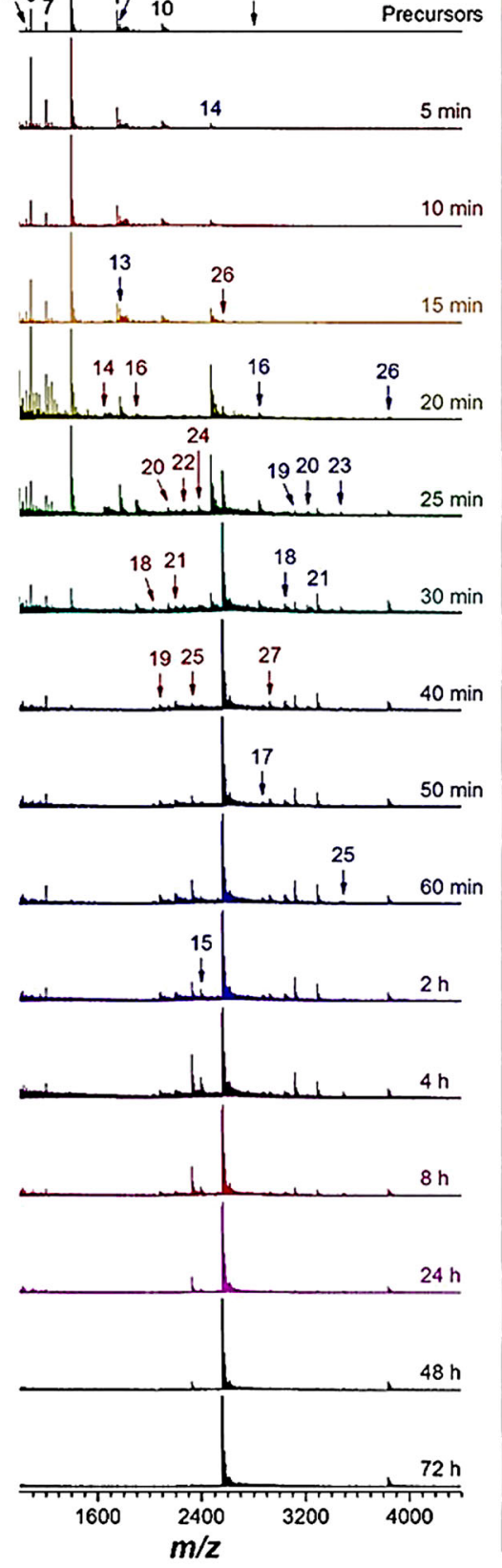

\section{Complex \\ precursors $\left(\mathrm{O}^{-}\right)$}

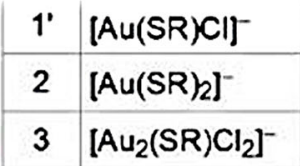

$4 \mathrm{Au}_{2}(\mathrm{SR})_{2}$

4' $\left[\mathrm{Au}_{2}(\mathrm{SR})_{2} \mathrm{Cl}\right]^{-}$

$\left.5 \mathrm{Au}_{2}(\mathrm{SR})_{3}\right]^{-}$

$6 \mathrm{Au}_{3}(\mathrm{SR})_{3}$

6' $\left[\mathrm{Au}_{3}(\mathrm{SR})_{3} \mathrm{Cl}\right]^{-}$

$7 \quad\left[\mathrm{Au}_{3}(\mathrm{SR})_{4}\right]^{-}$

$8 \mathrm{Au}_{4}(\mathrm{SR})_{4}$

$9 \quad \mathrm{Au}_{5}(\mathrm{SR})_{5}$

$10 \mathrm{Au}_{6}(\mathrm{SR})_{6}$

$11 \mathrm{Au}_{8}(\mathrm{SR})_{8}$

$12 \mathrm{Au}_{10}(\mathrm{SR})_{10}$

\begin{tabular}{|l|l|}
\hline \multicolumn{2}{|c|}{$2 e^{-}$-NC8 } \\
\hline 13 & $A u_{11}(S R)_{9}$ \\
\hline 14 & $A u_{15}(S R)_{13}$ \\
\hline
\end{tabular}

$14 \mathrm{Au}_{15}(\mathrm{SR})_{13}$

\section{$4 \theta^{-}$NCs}

$15\left[\mathrm{Au}_{15}(\mathrm{SR})_{12}\right]^{-}$

$16 \mathrm{Au}_{18}(\mathrm{SR})_{14}$

\begin{tabular}{|l|l|}
\hline \multicolumn{1}{|c|}{$6 \mathrm{e}^{-} \mathrm{NCs}$} \\
\hline 17 & $\mathrm{Au}_{19}(\mathrm{SR})_{13}$ \\
\hline 18 & $\mathrm{Au}_{20}(\mathrm{SR})_{14}$ \\
\hline 19 & {$\left[\mathrm{Au}_{20}(\mathrm{SR})_{15}\right]^{-}$} \\
\hline 20 & $\mathrm{Au}_{21}(\mathrm{SR})_{15}$ \\
\hline 21 & {$\left[\mathrm{Au}_{21}(\mathrm{SR})_{16}\right]^{-}$} \\
\hline 22 & $\mathrm{Au}_{22}(\mathrm{SR})_{16}$ \\
\hline 23 & {$\left[\mathrm{Au}_{22}(\mathrm{SR})_{17}\right]^{-}$} \\
\hline 24 & $\mathrm{Au}_{23}(\mathrm{SR})_{17}$ \\
\hline & $8 \mathrm{e}^{-} \mathrm{NCs}$ \\
\hline 25 & {$\left[\mathrm{Au}_{23}(\mathrm{SR})_{16}\right]^{-}$} \\
\hline 26 & {$\left[\mathrm{Au}_{25}(\mathrm{SR})_{18}\right]^{-}$} \\
\hline & $10 \mathrm{e}^{-} \mathrm{NCs}$ \\
\hline 27 & {$\left[\mathrm{Au}_{29}(\mathrm{SR})_{20}\right]^{-}$} \\
\hline
\end{tabular}

Fig. $13 \mathrm{ESI}$ MS showing stepwise growth of $\mathrm{Au}_{25}(\mathrm{SR})_{18}$ clusters. a Reaction scheme showing the formation of $\mathrm{Au}_{25}(\mathrm{SR})_{18}$ clusters from $\mathrm{Au}$ thiolates under the mild reducing environment of $\mathrm{CO}$. $\mathbf{b}$ Time-dependent UV-vis spectra, and $\mathbf{c}$ ESI MS during the formation of $\mathrm{Au}_{25}(\mathrm{SR})_{18} \mathrm{Clusters}$ from Au thiolates. ESI MS shows detection of several intermediate species (numbered 1-27), which are listed in the table presented on the right ${ }^{101}$. (Copyright ${ }^{\circ} 2014$ American Chemical Society) 

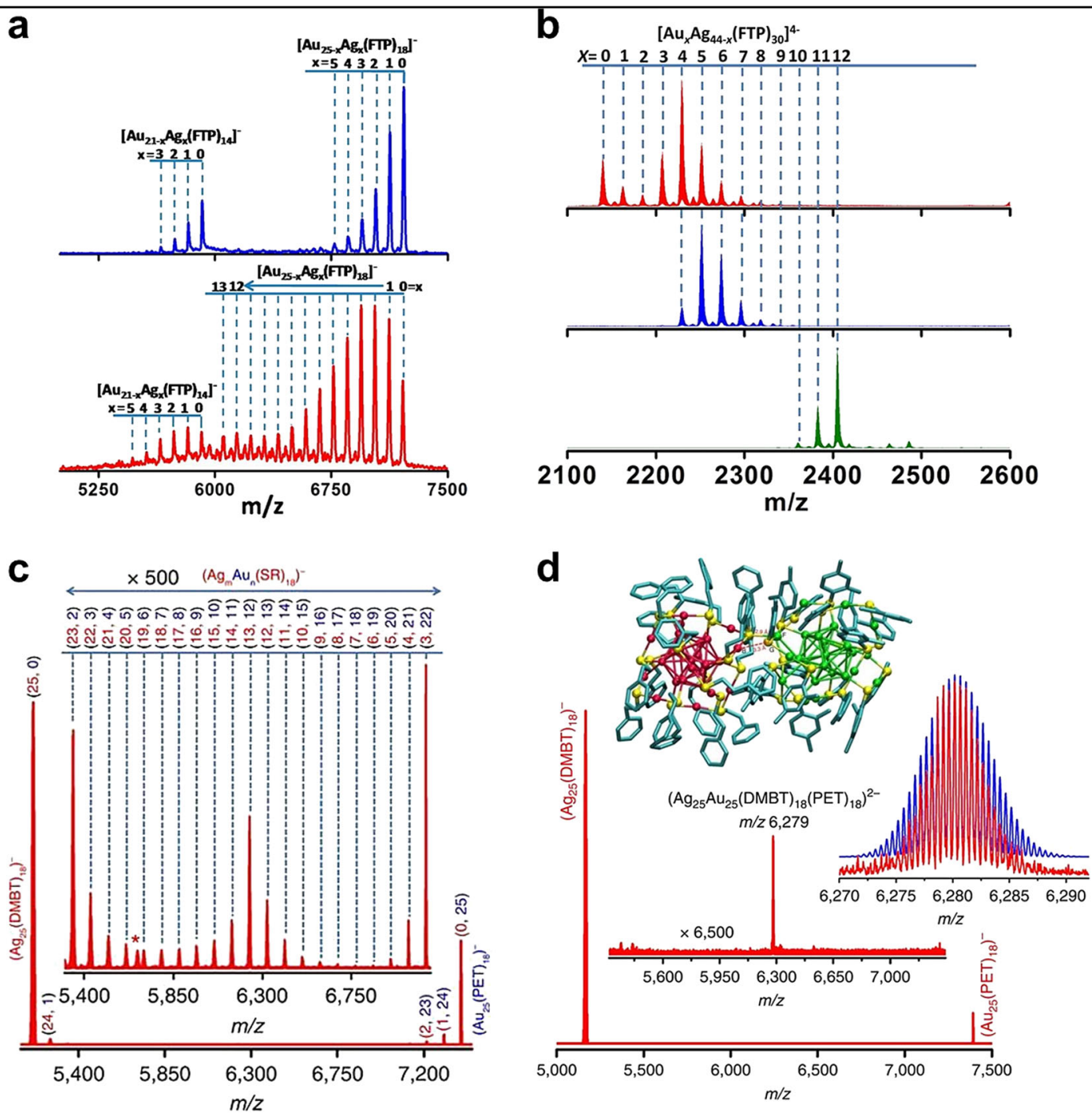

Fig. 14 Reactions between nanoparticles. a MALDI MS ${ }^{108}$ (Copyright ${ }^{\odot} 2016$ American Chemistry Society) and b ESI MS ${ }^{109}$ (Copyright $^{\odot} 2017$ American Chemical Society) data showing the mixture of alloys formed by inter-cluster reactions of $A_{25}(\mathrm{FTP})_{18}{ }^{-}$and $\mathrm{Ag}_{44}(\mathrm{FTP})_{30}{ }^{4-}$. c ESI MS showing the products of inter-cluster reaction of $\mathrm{Au}_{25}(\mathrm{PET})_{18}{ }^{-}$and $\mathrm{Ag}_{25}(\mathrm{DMBT})_{18}{ }^{-}$. $\mathbf{d}$ ESI MS of the dianionic adduct $\left[\mathrm{Ag}_{25} \mathrm{Au}_{25}(\mathrm{DMBT})_{18}(\mathrm{PET})_{18}\right]^{2-}$, detected at the early stages of reaction between $\mathrm{Au}_{25}(\mathrm{PET})_{18}{ }^{-}$and $\mathrm{Ag}_{25}(\mathrm{DMBT})_{18}{ }^{-}$. Insets show the comparison of the theoretical and experimental

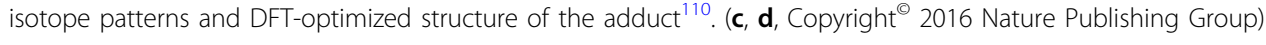

in sprays was observed before, bulk synthesis of molecules with which characterization is possible was not attempted earlier. Using a home-built nano-electrospray source, Sarkar et al. ${ }^{127}$ showed that spraying an aqueous solution of silver acetate (AgOAc) over a TEM grid, resulted in the formation of 1D nanowire structures of Ag NPs (Fig. 18). The precursors for the formation of the nanostructures were ions. Such studies unfold new routes of synthesis of materials using mass spectrometric interfaces ${ }^{127}$.

\section{Conclusions and future perspectives}

In conclusion, we have presented how MS has enriched the field of materials science; in particular, the field of monolayer-protected atomically precise NCs. From the discussion presented above, it becomes clear that MS has developed into a powerful tool for materials characterization, and it is expected to expand further in the future. MS as a technique is capable of building new interfaces which connects itself with independent disciplines. This has produced GC-MS, LC-MS, and their variations. New hyphenated methodologies and their power to understand structural details would expand further in the coming years. Combined with automation, synthesis of materials of atomic precision is expected to produce greater throughput in precision manufacture. Newer methods, utilizing the properties of molecular solids, and molecular building 
a

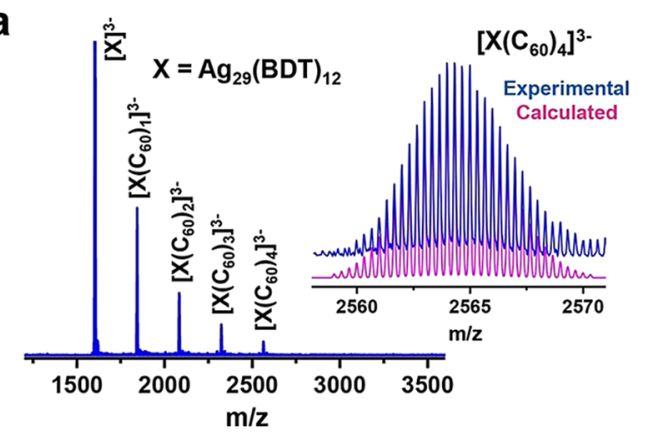

C

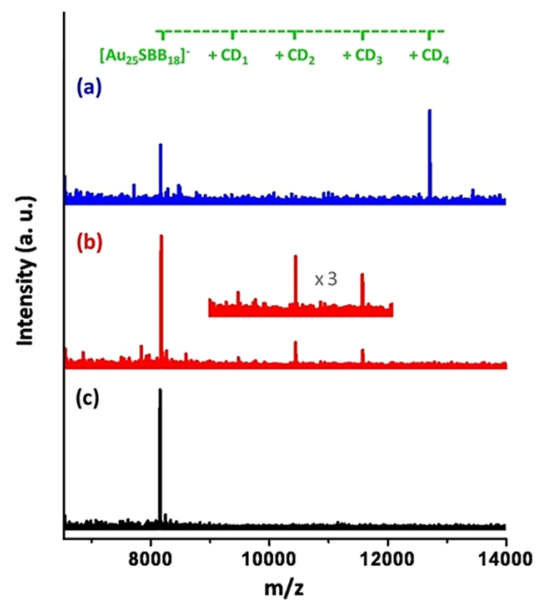

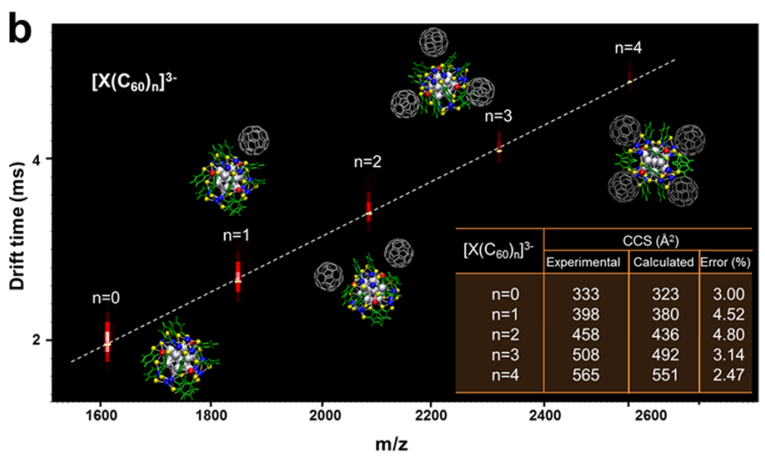

d

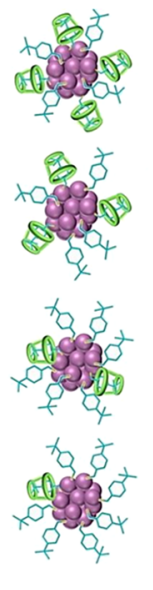

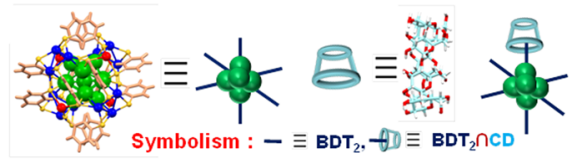

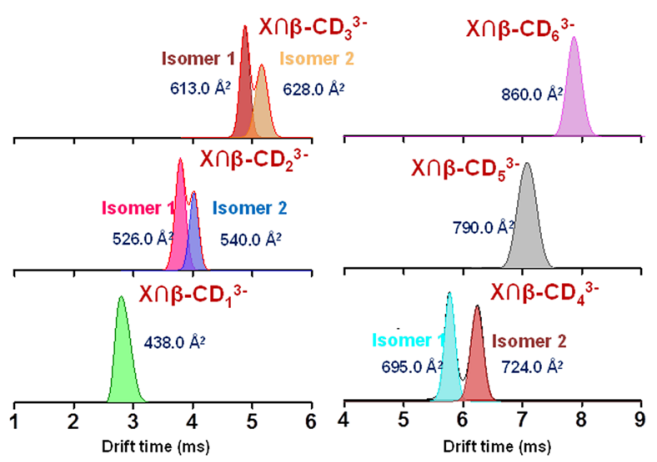

Fig. 15 Supramolecular chemistry of monolayer-protected noble metal clusters. a ESI MS of $\left[\mathrm{Ag}_{29}(\mathrm{BDT})_{12}\left(\mathrm{C}_{60}\right)_{n}\right]^{3-}(n=1-4)$ adducts. b IM-MS studies on $\left[\mathrm{Ag}_{29}(\mathrm{BDT})_{12}\left(\mathrm{C}_{60}\right)_{n}\right]^{3-}(n=1-4)$ showing the comparison of the experimental CCS values with the CCS values calculated for the lowest energy DFT-optimized structures ${ }^{113}$. (Copyright ${ }^{\circ} 2018$ American Chemical Society) $\mathbf{c}$ ESI MS of the inclusion complexes of CD with $\mathrm{Au}_{25}(\mathrm{SBB})_{18}$ cluster, $\left[\mathrm{Au}_{25}(\mathrm{SBB})_{18} \cap \mathrm{CD}_{n}\right]^{-}(n=1-4)$. Schematic structures of the species are also presented ${ }^{114}$. (Copyright ${ }^{\circ} 2014$ American Chemical Society) $\mathbf{d}$ IMMS studies showing the separation of isomers in $\left[\mathrm{Ag}_{29}\left(\mathrm{BDT}_{12} \cap \mathrm{CD}_{n}\right]^{3-}(n=1-6)\right.$ adducts $^{115}$. (Copyright ${ }^{\oplus} 2018$ American Chemical Society)

blocks such as infrared (IR) absorption will be important to study molecular interactions on such materials. Interfaces such as ion chromatography or PES could be built with the mass spectrometer, which can produce new information related to structural changes and associated electronic structure. As the science of the noble metal clusters is enriched by MS, a thorough study on these systems also reveals their potential to be used as mass spectrometric standards $^{128}$. Due to their high efficiency of ionization, distinct isotope patterns, stable intensities, and high $\mathrm{m} / \mathrm{z}$ values, they can be used as calibrants for mass spectrometers. This might help in overcoming the limitations of the lack of proper calibrants in the high mass range, and especially in the negative ion mode ${ }^{128}$.

Gas-phase IR in combination with IM-MS has recently gained importance in revealing the structural details of proteins. It has also proved to be powerful in understanding the geometries of other molecules such as the aggregates of protoporphyrin IX where IR spectroscopy confirmed that the pairing of carboxylic groups occurred during the formation of the stacked conformations ${ }^{129}$. Moreover, IM-MS in combination with IR has also been used in understanding the structures of isomers of small molecules like the N-protonated and O-protonated forms of benzocaine ${ }^{130}$, and structures of serine octamers ${ }^{129}$. In a similar manner, such studies may be extended in the case of clusters as well. Gas-phase IR can give more insights into the structure of the isomers or polymers of clusters. It can also be helpful for understanding interactions in the case of supramolecular adducts of clusters.

Spectroscopy and dynamics of trapped clusters ions, produced inside the mass spectrometer, can present new insights into their electronic structure. Trapped ion electron diffraction may be used for determining structures of noble metal NCs. Other possibilities include studies such as trapped ion laser-induced fluorescence. Spectroscopy of isolated cluster ions like electron detachment spectroscopy, PES, and single-particle fluorescence may be explored for a wide range of ligandprotected clusters. Such studies may even be done on 

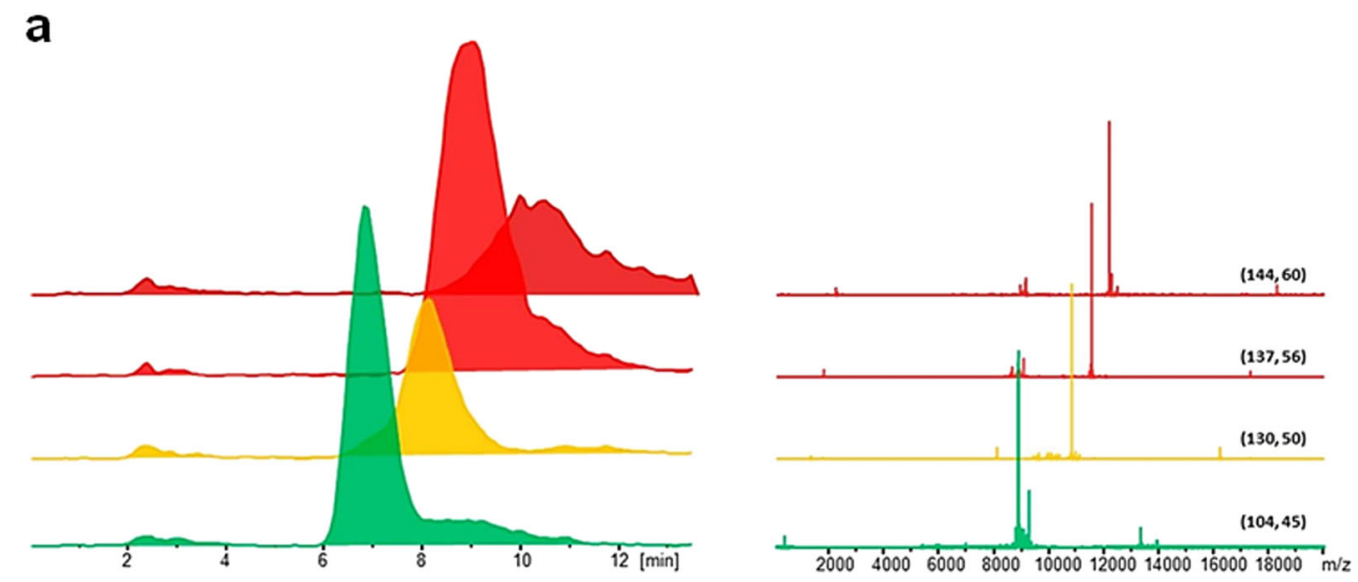

b

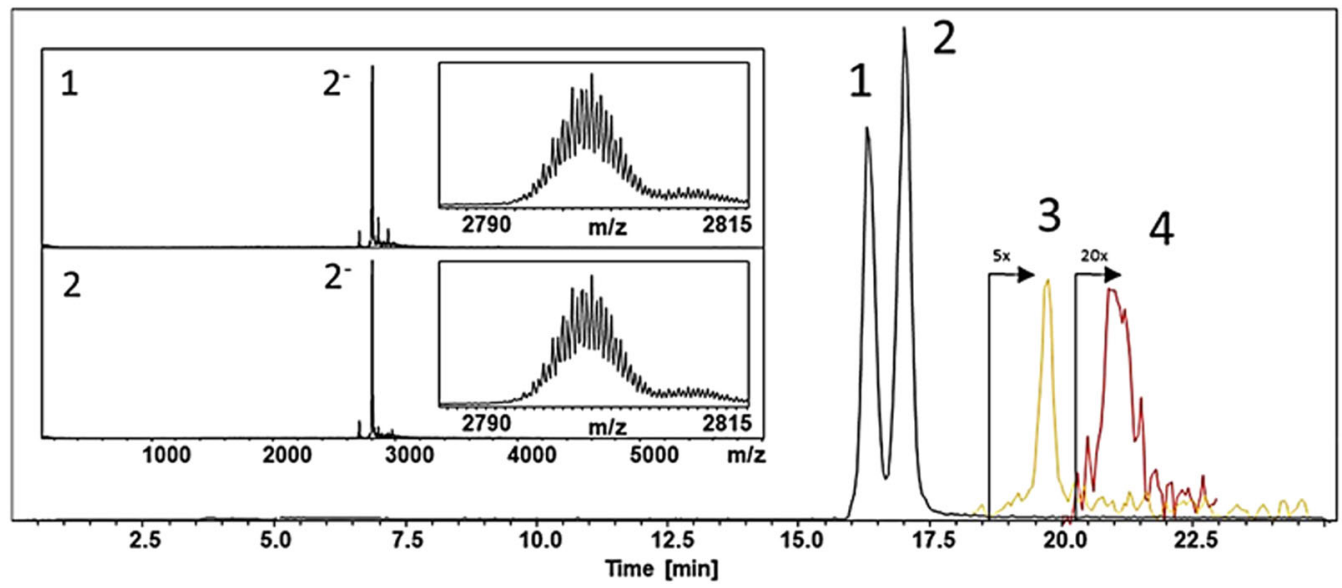

Fig. 16 Liquid chromatography (LC) MS on clusters. a Extracted ion chromatograms corresponding to $A_{104} \mathrm{~L}_{45}, A_{u_{130}} \mathrm{~L}_{50}, \mathrm{Au}_{137} \mathrm{~L}_{56}$, and $A u_{144} \mathrm{~L}_{60}$

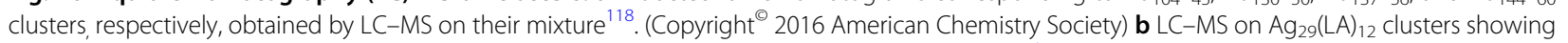
the separation of the two isomers. Peaks 3 and 4 correspond to dimer- and trimer-like species ${ }^{119}$. (Copyright ${ }^{\circ} 2018$ American Chemistry Society)

specific isomers of the clusters to obtain isomer-specific properties. Catalysis of isolated cluster ions may be studied. Ion soft landing may be used to deposit ligandprotected cluster ions on specific substrates.

Extensive studies can also be done with clusters synthesized in macromolecular templates like proteins ${ }^{131}$, $\mathrm{DNAs}^{132}$, etc., which are of particular interest because of their biocompatibility. Till now, most of the proteinprotected clusters are mainly characterized by MS due to the difficulty in their crystallization. Though this aspect has not been discussed in detail in this review, enormous literature exists on the use of MS in understanding their composition, mechanism of growth, etc. ${ }^{131,133}$. MS has always been effective in revealing structural details of proteins. In a similar way such studies can be extended to clusters synthesized in protein templates.

With such enormous possibilities, the proliferation of MS into materials science could make it an indispensable tool in that branch of science as has happened with TEM. This would produce new demands for instrumentation, associated interfaces, calibration standards, and associated needs. Expanding the limits of mass spectrometry in mass range and resolution would push traditional analytical methods further. Depending on the properties of such materials, possibilities to do catalysis, IR spectroscopy, fluorescence spectroscopy, and electron diffraction in mass spectrometers, as discussed above, could expand our understanding of phenomena to even greater detail.

\section{Acknowledgements}

P.C. thanks Council of Scientific and Industrial Research (CSIR) for her research fellowship. We acknowledge the Department of Science and Technology (DST), Government of India for supporting our research program.

Conflict of interest

The authors declare that they have no conflict of interest. 
a

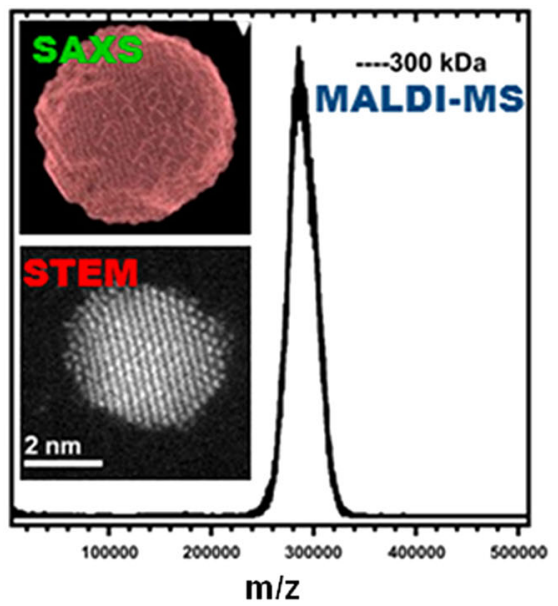

b

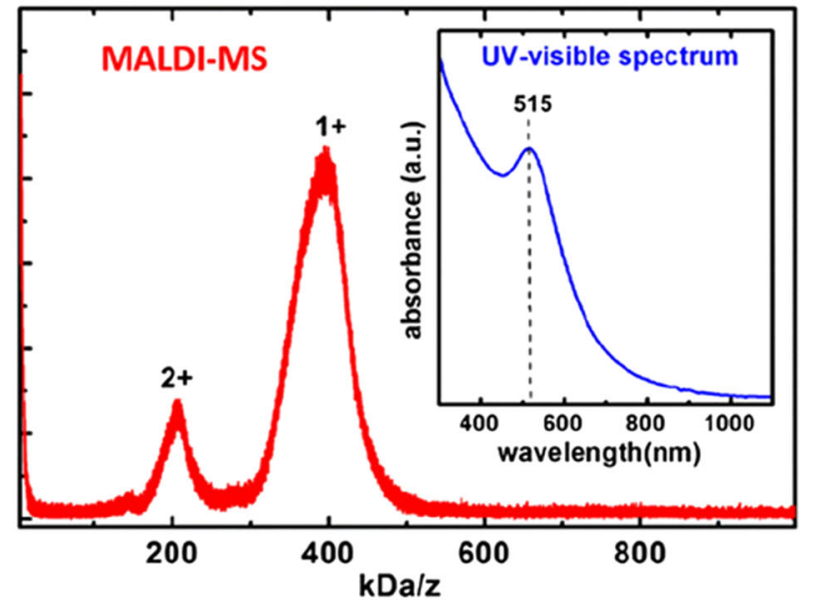

Fig. 17 MS of nanoparticles. a MALDI MS of Au-1400 ( $300 \mathrm{kDa})$ nanoparticle. SAXS molecular envelope and STEM images of the nanoparticle are shown in the insets ${ }^{123}$. (Copyright ${ }^{\circ} 2018$ American Chemistry Society) b MALDI MS of $A_{\sim 2000}\left(\mathrm{SC}_{6} \mathrm{H}_{13}\right)_{\sim 290}(\sim 400 \mathrm{kDa})$ nanoparticle. UV-vis spectrum of the nanoparticle is presented in the inset ${ }^{124}$. Copyright $^{\odot} 2018$ American Chemistry Society)

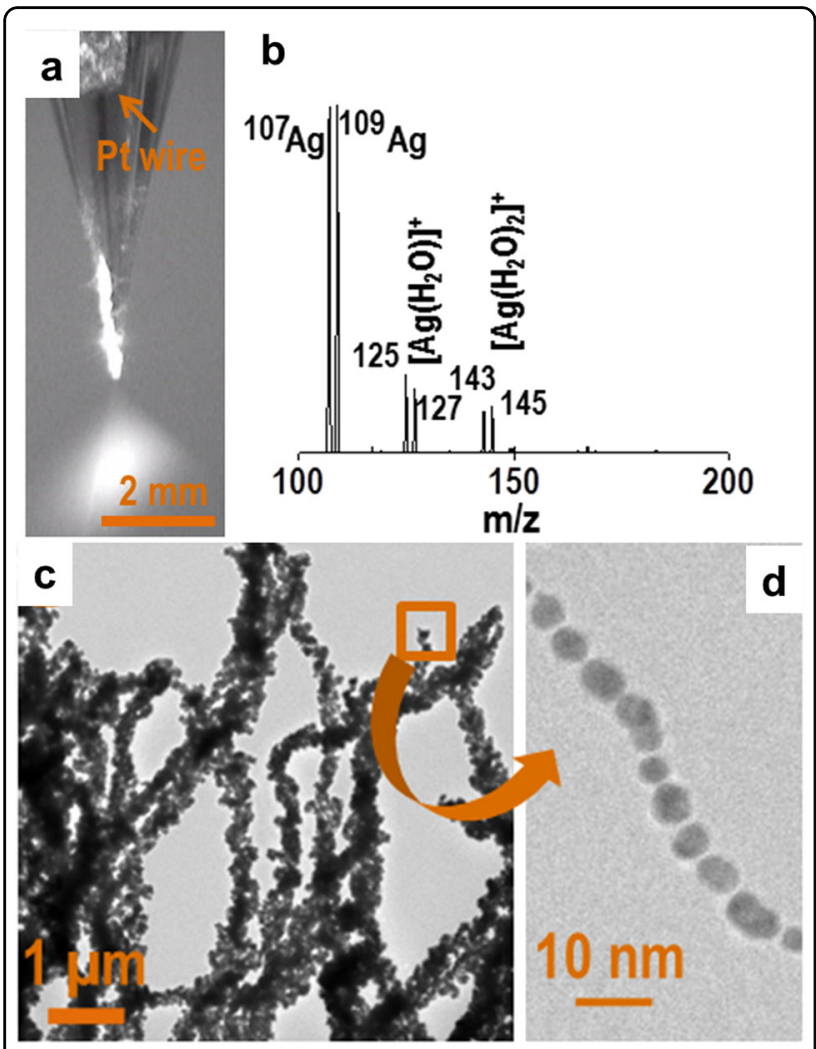

Fig. 18 Synthesis of materials using mass spectrometric tools. a Optical image of electrospray of AgOAc solution. $\mathbf{b}$ Mass spectra of the spray showing the presence of $\mathrm{Ag}$ and its hydrated $\mathrm{Ag}$ ions. c TEM image and $\mathbf{d}$ HRTEM of brush-like structures formed by electrospraying the AgOAc solution on a TEM grid ${ }^{127}$. (Copyright 2016 John Wiley and Sons)

\section{Publisher's note}

Springer Nature remains neutral with regard to jurisdictional claims in published maps and institutional affiliations.

Received: 4 February 2019 Revised: 5 May 2019 Accepted: 20 May 2019. Published online: 20 September 2019

\section{References}

1. Fenn, J. B., Mann, M., Meng, C. K., Wong, S. F. \& Whitehouse, C. M. Electrospray ionization for mass spectrometry of large biomolecules. Science 246, 64 (1989).

2. Wenzel, R. J., Matter, U., Schultheis, L. \& Zenobi, R. Analysis of megadalton ions using cryodetection MALDI time-of-flight mass spectrometry. Anal. Chem. 77, 4329-4337 (2005).

3. Thomson, J. J. Bakerian lecture:-rays of positive electricity. Proc. R. Soc. A $\mathbf{8 9}$ $1-20(1913)$.

4. Thomas, J. M. J. J. Thomson: winner of the Nobel Prize for physics 1906 Angew. Chem. Int. Ed. 45, 6797-6800 (2006).

5. Aston, F. W. Isotopes. London: Edward Arnold, 252 (E. Arnold \& Company, London 1922).

6. McLafferty, F. W. A century of progress in molecular mass spectrometry. Ann Rev. Anal. Chem. 4, 1-22 (2011).

7. Gohlke, R. S. Time-of-flight mass spectrometry and gas-liquid partition chromatography. Anal. Chem. 31, 535-541 (1959).

8. Gohlke, R. S. \& McLafferty, F. W. Early gas chromatography/mass spectrometry. J. Am. Soc. Mass Spectrom. 4, 367-371 (1993).

9. McLafferty, F. W., Todd, P. J., McGilvery, D. C. \& Baldwin, M. A. Collisional activation and metastable ion characteristics. High-resolution tandem mass spectrometer (MS/MS) of increased sensitivity and mass range. J. Am. Chem. Soc. 102, 3360-3363 (1980)

10. Tanaka, K. et al. Protein and polymer analyses up to $\mathrm{m} / \mathrm{z} 100000$ by laser ionization time-of-flight mass spectrometry. Rapid Commun. Mass Spectrom. 2, 151-153 (1988).

11. Xian, F., Hendrickson, C. L. \& Marshall, A. G. High resolution mass spectrometry. Anal. Chem. 84, 708-719 (2012).

12. Cameron, A. E., Eggers Jr, D. F. An ion "Velocitron". Rev. Sci. Instrum. 19, 605-607 (1948).

13. Comisarow, M. B. \& Marshall, A. G. Fourier transform ion cyclotron resonance spectroscopy. Chem. Phys. Lett. 25, 282-283 (1974).

14. Makarov, A. Electrostatic axially harmonic orbital trapping: a highperformance technique of mass analysis. Anal. Chem. 72, 1156-1162 (2000). 
15. Makarov, A., Denisov, E. \& Lange, O. Performance evaluation of a high-field orbitrap mass analyzer. J. Am. Soc. Mass Spectrom. 20, 1391-1396 (2009).

16. Nolting, D., Malek, R. \& Makarov, A. Ion traps in modern mass spectrometry. Mass Spectrom. Rev. 0, 1-19 (2017).

17. Bunaciu, A. A., Udriştioiu, Eg \& Aboul-Enein, H. Y. X-ray diffraction: instrumentation and applications. Crit. Rev. Anal. Chem. 45, 289-299 (2015).

18. McLafferty, F. W. Tandem mass spectrometry (MS/MS): a promising new analytical technique for specific component determination in complex mixtures. Acc. Chem. Res. 13, 33-39 (1980).

19. Elyashberg, M. Identification and structure elucidation by NMR spectroscopy. TrAC Trends Anal. Chem. 69, 88-97 (2015).

20. Kwan, E. E. \& Huang, S. G. Structural elucidation with NMR spectroscopy: practical strategies for organic chemists. Eur. J. Org. Chem. 2008, 2671-2688 (2008).

21. Pauling, L. The Nature of the Chemical Bond and the Structure of Molecules and Crystals: An Introduction to Modern Structural Chemistry. Third Edition (Cornell University Press, Ithaca, New York, 1960).

22. Harkness, K. M., Cliffel, D. E. \& McLean, J. A. Characterization of thiolateprotected gold nanoparticles by mass spectrometry. Analyst 135, 868-874 (2010).

23. Lu, Y. \& Chen, W. Application of mass spectrometry in the synthesis and characterization of metal nanoclusters. Anal. Chem. 87, 10659-10667 (2015).

24. Johnson, G. E. \& Laskin, J. Understanding ligand effects in gold clusters using mass spectrometry. Analyst 141, 3573-3589 (2016).

25. Chakraborty, I. \& Pradeep, T. Atomically precise clusters of noble metals: emerging link between atoms and nanoparticles. Chem. Rev. 117, 8208-8271 (2017)

26. Jin, R., Zeng, C., Zhou, M. \& Chen, Y. Atomically precise colloidal metal nanoclusters and nanoparticles: fundamentals and opportunities. Chem. Rev. 116, 10346-10413 (2016).

27. Heaven, M. W., Dass, A., White, P. S., Holt, K. M. \& Murray, R. W. Crystal structure of the gold nanoparticle $\left[\mathrm{N}_{(}\left(\mathrm{C}_{8} \mathrm{H}_{17}\right)_{4}\right]\left[\mathrm{Au}_{25}\left(\mathrm{SCH}_{2} \mathrm{CH}_{2} \mathrm{Ph}\right)_{18}\right]$. J. Am. Chem. Soc. 130, 3754-3755 (2008).

28. Zeng, C., Li, T., Das, A., Rosi, N. L. \& Jin, R. Chiral structure of thiolate-protected 28-gold-atom nanocluster determined by X-ray crystallography. J. Am. Chem. Soc. 135, 10011-10013 (2013).

29. Qian, H., Eckenhoff, W. T., Zhu, Y., Pintauer, T. \& Jin, R. Total structure determination of thiolate-protected $\mathrm{Au}_{38}$ nanoparticles. J. Am. Chem. Soc. 132 8280-8281 (2010).

30. Malola, S. et al. $\mathrm{Au}_{40}(\mathrm{SR})_{24}$ cluster as a chiral dimer of 8-electron superatoms: structure and optical properties. J. Am. Chem. Soc. 134, 19560-19563 (2012).

31. Zeng, $\mathrm{C}$. et al. Gold tetrahedra coil up: Kekulé-like and double helical superstructures. Sci. Adv. 1, e1500425 (2015).

32. Zeng, C., Liu, C., Chen, Y., Rosi, N. L. \& Jin, R. Atomic structure of selfassembled monolayer of thiolates on a tetragonal $\mathrm{Au}_{92}$ nanocrystal. J. Am. Chem. Soc. 138, 8710-8713 (2016).

33. Jadzinsky, P. D., Calero, G., Ackerson, C. J., Bushnell, D. A. \& Kornberg, R. D. Structure of a thiol monolayer-protected gold nanoparticle at $1.1 \AA$ resolution. Science 318, 430-433 (2007).

34. Dass, $\mathrm{A}$. et $\mathrm{al} . \mathrm{Au}_{133}\left(\mathrm{SPh}-{ }^{\mathrm{t}} \mathrm{Bu}\right)_{52}$ nanomolecules: X-ray crystallography, optical, electrochemical, and theoretical analysis. J. Am. Chem. Soc. 137, 4610-4613 (2015).

35. Desireddy, A. et al. Ultrastable silver nanoparticles. Nature 501, 399 (2013).

36. Joshi, C. P., Bootharaju, M. S., Alhilaly, M. J. \& Bakr, O. M. $\left[\operatorname{Ag}_{25}(\mathrm{SR})_{18}\right]^{-}$: the "Golden" silver nanoparticle. J. Am. Chem. Soc. 137, 11578-11581 (2015).

37. AbdulHalim, L. G. et al. $\mathrm{Ag}_{29}(\mathrm{BDT})_{12}(\mathrm{TPP})_{4}$ : a tetravalent nanocluster. J. Am. Chem. Soc. 137, 11970-11975 (2015).

38. Kroto, H. W., Heath, J. R., O'Brien, S. C., Curl, R. F. \& Smalley, R. E. C6o: buckminsterfullerene. Nature 318, 162 (1985)

39. Knight, W. D. et al. Electronic shell structure and abundances of sodium clusters. Phys. Rev. Lett. 52, 2141-2143 (1984).

40. Maruyama, S., Kohno, M. \& Inoue, S. FT-ICR study of chemical reaction of silicon clusters. Therm. Sci. Eng. 7, 1-6 (1999).

41. Singh, D. M. D. J., Pradeep, T., Bhattacharjee, J. \& Waghmare, U. V. Closed-cage clusters in the gaseous and condensed phases derived from sonochemically synthesized MoS, nanoflakes. J. Am. Soc. Mass Spectrom. 18, 2191-2197 (2007).

42. Katakuse, I. et al. Mass distributions of negative cluster ions of copper, silver, and gold. Int. J. Mass Spectrom. Ion-. Process. 74, 33-41 (1986).

43. Furche, F. et al. The structures of small gold cluster anions as determined by a combination of ion mobility measurements and density functional calculations. J. Chem. Phys. 117, 6982-6990 (2002).
44. Lechtken, A., Neiss, C., Kappes, M. M. \& Schooss, D. Structure determination of gold clusters by trapped ion electron diffraction: $\mathrm{Au}_{14}{ }^{-}-\mathrm{Au}_{19}{ }^{-}$. Phys. Chem. Chem. Phys. 11, 4344-4350 (2009).

45. Li, J., Li, X., Zhai, H.-J. \& Wang, L.-S. Auzo: a tetrahedral cluster. Science 299, 864 (2003)

46. Brust, M., Walker, M., Bethell, D., Schiffrin, D. J. \& Whyman, R. Synthesis of thiolderivatised gold nanoparticles in a two-phase liquid-liquid system. J. Chem. Soc., Chem. Commun., 801-802 (1994).

47. Whetten, R. L. et al. Nanocrystal gold molecules. Adv. Mat. 8, 428-433 (1996).

48. Schaaff, T. G., Knight, G., Shafigullin, M. N., Borkman, R. F. \& Whetten, R. L. Isolation and selected properties of a $10.4 \mathrm{kDa}$ gold:glutathione cluster compound. J. Phys. Chem. B 102, 10643-10646 (1998).

49. Negishi, Y., Nobusada, K. \& Tsukuda, T. Glutathione-protected gold clusters revisited: bridging the gap between gold(I)-thiolate complexes and thiolate-protected gold nanocrystals. J. Am. Chem. Soc. 127, 5261-5270 (2005)

50. Tracy, J. B. et al. Poly(ethylene glycol) ligands for high-resolution nanoparticle mass spectrometry. J. Am. Chem. Soc. 129, 6706-6707 (2007).

51. Negishi, Y., Chaki, N. K., Shichibu, Y., Whetten, R. L. \& Tsukuda, T. Origin of magic stability of thiolated gold clusters: a case study on $\mathrm{Au}_{25}\left(\mathrm{SC}_{6} \mathrm{H}_{13}\right)_{18}$. J. Am. Chem. Soc. 129, 11322-11323 (2007).

52. Dass, A., Stevenson, A., Dubay, G. R., Tracy, J. B. \& Murray, R. W. Nanoparticle MALDI-TOF mass spectrometry without fragmentation: $\mathrm{Au}_{25}\left(\mathrm{SCH}_{2} \mathrm{CH}_{2} \mathrm{Ph}\right)_{18}$ and mixed monolayer $\mathrm{Au}_{25}\left(\mathrm{SCH}_{2} \mathrm{CH}_{2} \mathrm{Ph}\right)_{18-x}(\mathrm{~L})_{x}$. J. Am. Chem. Soc. 130, 5940-5946 (2008).

53. Qian, H., Zhu, Y. \& Jin, R. Atomically precise gold nanocrystal molecules with surface plasmon resonance. Proc. Natl. Acad. Sci. 109, 696-700 (2012).

54. Levi-Kalisman, $Y$. et al. Synthesis and characterization of $A_{u_{102}}(p-M B A)_{44}$ nanoparticles. J. Am. Chem. Soc. 133, 2976-2982 (2011).

55. Wu, Z. et al. High yield, large scale synthesis of thiolate-protected $\mathrm{Ag}_{7}$ clusters. J. Am. Chem. Soc. 131, 16672-16674 (2009).

56. Udaya Bhaskara Rao, T. \& Pradeep, T. Luminescent $\mathrm{Ag}_{7}$ and $\mathrm{Ag}_{8}$ clusters by interfacial synthesis. Angew. Chem. 49, 3925-3929 (2010).

57. Baksi, A., Bootharaju, M. S., Chen, X., Häkkinen, H. \& Pradeep, T. $\operatorname{Ag}_{11}(S G)_{7}$ : a new cluster identified by mass spectrometry and optical spectroscopy. J. Phys. Chem. C. 118, 21722-21729 (2014).

58. Bertorelle, F. et al. Synthesis, characterization and optical properties of low nuclearity liganded silver clusters: $\mathrm{Ag}_{31}(\mathrm{SG})_{19}$ and $\mathrm{Ag}_{15}(\mathrm{SG})_{11}$. Nanoscale $\mathbf{5}$, 5637-5643 (2013).

59. Udayabhaskararao, T., Bootharaju, M. S. \& Pradeep, T. Thiolate-protected $\mathrm{Ag}_{32}$ clusters: mass spectral studies of composition and insights into the Agthiolate structure from NMR. Nanoscale 5, 9404-9411 (2013).

60. Harkness, K. M. et al. $\mathrm{Ag}_{44}(\mathrm{SR})_{30}{ }^{4-}$ : a silver-thiolate superatom complex. Nanoscale 4, 4269-4274 (2012).

61. Yang, $\mathrm{H}$. et al. All-thiol-stabilized $\mathrm{Ag}_{44}$ and $\mathrm{Au}_{12} \mathrm{Ag}_{32}$ nanoparticles with single-crystal structures. Nat. Commun. 4, 2422 (2013).

62. Alhilaly, M. J. et al. $\left[\mathrm{Ag}_{67}\left(\mathrm{SPhMe}_{2}\right)_{32}\left(\mathrm{PPh}_{3}\right)_{8}\right]^{3+}$ : synthesis, total structure, and optical properties of a large box-shaped silver nanocluster. J. Am. Chem. Soc. 138, 14727-14732 (2016).

63. Bootharaju, M. S. et al. A new class of atomically precise, hydride-rich silver nanoclusters co-protected by phosphines. J. Am. Chem. Soc. 138, 13770-13773 (2016).

64. Takano, S., Hirai, H., Muramatsu, S. \& Tsukuda, T. Hydride-doped gold superatom $\left(\mathrm{Au}_{9} \mathrm{H}\right)^{2+}$ : synthesis, structure, and transformation. J. Am. Chem. Soc. 140, 8380-8383 (2018).

65. Takano, S., Hirai, H., Muramatsu, S. \& Tsukuda, T. Hydride-mediated controlled growth of a bimetallic $\left(\mathrm{Pd} @ \mathrm{Au}_{8}\right)^{2+}$ superatom to a hydride-doped

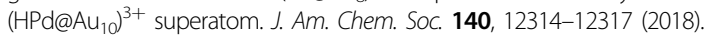

66. Le Guével, X., Trouillet, V., Spies, C., Jung, G. \& Schneider, M. Synthesis of yellow-emitting platinum nanoclusters by ligand etching. J. Phys. Chem. C. 116, 6047-6051 (2012).

67. Tanaka, S.-I., Miyazaki, J., Tiwari, D. K., Jin, T. \& Inouye, Y. Fluorescent platinum nanoclusters: synthesis, purification, characterization, and application to bioimaging. Angew. Chem. 50, 431-435 (2011).

68. Zamborini, F. P., Gross, S. M. \& Murray, R. W. Synthesis, characterization, reactivity, and electrochemistry of palladium, monolayer protected clusters. Langmuir 17, 481-488 (2001).

69. Negishi, Y., Murayama, H. \& Tsukuda, T. Formation of $\mathrm{Pd}_{n}(\mathrm{SR})_{m}$ clusters $(n<$ 60) in the reactions of $\mathrm{PdCl}_{2}$ and $\mathrm{RSH}\left(\mathrm{R}=\mathrm{n}-\mathrm{C}_{18} \mathrm{H}_{37}, \mathrm{n}-\mathrm{C}_{12} \mathrm{H}_{25}\right)$. Chem. Phys. Lett. 366, 561-566 (2002) 
70. Chen, J., Pan, Y., Wang, Z. \& Zhao, P. The fluorescence properties of tiara like structural thiolated palladium clusters. Dalton Trans. 46, 12964-12970 (2017).

71. Dhayal, R. S. et al. Diselenophosphate-induced conversion of an achiral $\left[\mathrm{Cu}_{20} \mathrm{H}_{11}\left\{\mathrm{~S}_{2} \mathrm{P}(\mathrm{OiPr})_{2}\right\}_{9}\right]$ into a chiral $\left[\mathrm{Cu}_{20} \mathrm{H}_{11}\left\{\mathrm{Se}_{2} \mathrm{P}\left(\mathrm{O}^{\prime} \mathrm{Pr}\right)_{2}\right\}_{9}\right]$ polyhydrido nanocluster. Angew. Chem. 54, 13604-13608 (2015).

72. Araake, R., Sakadani, K., Tada, M., Sakai, Y. \& Ohki, Y. $\left[\mathrm{Fe}_{4}\right]$ and $\left[\mathrm{Fe}_{6}\right]$ hydride clusters supported by phosphines: synthesis, characterization, and application in $\mathrm{N}_{2}$ reduction. J. Am. Chem. Soc. 139, 5596-5606 (2017).

73. Bhat, $\mathrm{S}$. et al. Atomically precise and monolayer protected iridium clusters in solution. RSC Adv. 6, 26679-26688 (2016).

74. Lanucara, F., Holman, S. W., Gray, C. J. \& Eyers, C. E. The power of ion mobilitymass spectrometry for structural characterization and the study of conformational dynamics. Nat. Chem. 6, 281 (2014).

75. Canzani, D., Laszlo, K. J. \& Bush, M. F. lon mobility of proteins in nitrogen gas: effects of charge state, charge distribution, and structure. J. Phys. Chem. A 122, 5625-5634 (2018).

76. Greisch, J.-F. et al. From planar to cage in 15 easy steps: resolving the $\mathrm{C}_{60} \mathrm{H}_{21} \mathrm{~F}_{9}{ }^{-} \rightarrow \mathrm{C}_{60}{ }^{-}$transformation by ion mobility mass spectrometry. J. Am Chem. Soc. 138, 11254-11263 (2016).

77. Surman, A. J. et al. Sizing and discovery of nanosized polyoxometalate clusters by mass spectrometry. J. Am. Chem. Soc. 138, 3824-3830 (2016).

78. Baksi, A., Chakraborty, P., Bhat, S., Natarajan, G. \& Pradeep, T. $\left[\mathrm{Au}_{25}(\mathrm{SR})_{18}\right]_{2}{ }^{2-}$ : a noble metal cluster dimer in the gas phase. Chem. Commun. 52, 8397-8400 (2016).

79. Chakraborty, P. et al. Understanding proton capture and cation-induced dimerization of $\left[\mathrm{Ag}_{29}(\mathrm{BDT})_{12}\right]^{3-}$ clusters by ion mobility mass spectrometry. Phys. Chem. Chem. Phys. 20, 7593-7603 (2018).

80. Baksi, A., Harvey, S. R., Natarajan, G., Wysocki, V. H. \& Pradeep, T. Possible isomers in ligand protected $\mathrm{Ag}_{11}$ cluster ions identified by ion mobility mass spectrometry and fragmented by surface induced dissociation. Chem. Commun. 52, 3805-3808 (2016).

81. Baksi, A. et al. Isomerism in monolayer protected silver cluster ions: an ion mobility-mass spectrometry approach. J. Phys. Chem. C. 121, 13421-13427 (2017).

82. Gillb, S., Weis, P., Furche, F., Ahlrichs, R. \& Kappes, M. M. Structures of small gold cluster cations $\left(\mathrm{Au}_{\mathrm{n}}{ }^{+}, \mathrm{n}<14\right)$ : ion mobility measurements versus density functional calculations. J. Chem. Phys. 116, 4094-4101 (2002).

83. Daly, S. et al. Gas-phase structural and optical properties of homo- and heterobimetallic rhombic dodecahedral nanoclusters $\left[\mathrm{Ag}_{14-n} \mathrm{Cu}_{n}\left(\mathrm{C} \equiv \mathrm{C}^{\mathrm{t}} \mathrm{Bu}\right)_{12} \mathrm{X}\right]^{+}(\mathrm{X}=\mathrm{Cl}$ and $\mathrm{Br})$ : Ion mobility, VUV and UV spectroscopy, and DFT calculations. J. Phys. Chem. C. 121, 10719-10727 (2017).

84. Soleilhac, A. et al. Size characterization of glutathione-protected gold nanoclusters in the solid, liquid and gas phases. J. Phys. Chem. C. 121, 27733-27740 (2017).

85. Ligare, M. R., Baker, E. S., Laskin, J. \& Johnson, G. E. Ligand induced structural isomerism in phosphine coordinated gold clusters revealed by ion mobility mass spectrometry. Chem. Commun. 53, 7389-7392 (2017).

86. Hirata, K. et al. Interconversions of structural isomers of $\left[\mathrm{PdAu} u_{8}\left(\mathrm{PPh}_{3}\right)_{8}\right]^{2+}$ and $\left[\mathrm{Au}_{9}\left(\mathrm{PPh}_{3}\right)_{8}\right]^{3+}$ revealed by ion mobility mass spectrometry. J. Phys. Chem. C. 122, 23123-23128 (2018).

87. Fields-Zinna, C. A. et al. Tandem mass spectrometry of thiolate-protected $\mathrm{Au}$

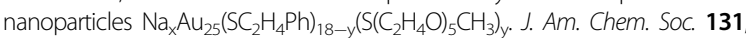
13844-13851 (2009).

88. Angel, L. A., Majors, L. T., Dharmaratne, A. C. \& Dass, A. lon mobility mass spectrometry of $\mathrm{Au}_{25}\left(\mathrm{SCH}_{2} \mathrm{CH}_{2} \mathrm{Ph}\right)_{18}$ nanoclusters. ACS Nano 4, 4691-4700 (2010).

89. Black, D. M., Bhattarai, N., Whetten, R. L. \& Bach, S. B. H. Collision-induced dissociation of monolayer protected clusters $\mathrm{Au}_{144}$ and $\mathrm{Au}_{130}$ in an electrospray time-of-flight mass spectrometer. J. Phys. Chem. A 118, 10679-10687 (2014).

90. Tomihara, R. et al. Collision-induced dissociation of undecagold clusters protected by mixed ligands $\left[\mathrm{Au}_{11}\left(\mathrm{PPh}_{3}\right)_{8} \mathrm{X}_{2}\right]^{+}(\mathrm{X}=\mathrm{Cl}, \mathrm{C} \equiv \mathrm{CPh})$. ACS Omega $\mathbf{3}$, 6237-6242 (2018).

91. Chakraborty, P. et al. Dissociation of gas phase ions of atomically precise silver clusters reflects their solution phase stability. J. Phys. Chem. C. 121, 10971-10981 (2017).

92. Johnson, G. E., Priest, T. \& Laskin, J. Size-dependent stability toward dissociation and ligand binding energies of phosphine ligated gold cluster ions. Chem. Sci. 5, 3275-3286 (2014).

93. Black, D. M., Crittenden, C. M., Brodbelt, J. S. \& Whetten, R. L. Ultraviolet photodissociation of selected gold clusters: ultraefficient unstapling and ligand stripping of $\mathrm{Au}_{25}(\mathrm{pMBA})_{18}$ and $\mathrm{Au}_{36}(\mathrm{pMBA})_{24}$. J. Phys. Chem. Lett. 8 1283-1289 (2017).

94. Ghosh, A. et al. Sequential dihydrogen desorption from hydride-protected atomically precise silver clusters and the formation of naked clusters in the gas phase. ACS Nano 11, 11145-11151 (2017).

95. Jash, M. et al. Preparation of gas phase naked silver cluster cations outside a mass spectrometer from ligand protected clusters in solution. Nanoscale $\mathbf{1 0}$, 15714-15722 (2018).

96. Wang, L.-M. \& Wang, L.-S. Probing the electronic properties and structural evolution of anionic gold clusters in the gas phase. Nanoscale 4, 4038-4053 (2012).

97. Hirata, $\mathrm{K}$. et al. Anion photoelectron spectroscopy of free $\left[\mathrm{Au}_{25}\left(\mathrm{SC}_{12} \mathrm{H}_{25}\right)_{18}\right]^{-}$. Nanoscale 9, 13409-13412 (2017).

98. Hamouda, R. et al. Electron emission of gas-phase $\left[\mathrm{Au}_{25}(\mathrm{SG})_{18}-6 \mathrm{H}\right]^{7-}$ gold cluster and its action spectroscopy. J. Phys. Chem. Lett. 1, 3189-3194 (2010).

99. Daly, S. et al. Gas-phase VUV photoionisation and photofragmentation of the silver deuteride nanocluster $\left[\mathrm{Ag}_{10} \mathrm{D}_{8} \mathrm{~L}_{6}\right]^{2+} \quad(\mathrm{L}=\mathrm{bis}$ (diphenylphosphino) methane). A joint experimental and theoretical study. Phys. Chem. Chem. Phys. 17, 25772-25777 (2015).

100. Yu, Y., Luo, Z., Yu, Y., Lee, J. Y. \& Xie, J. Observation of cluster size growth in CO-directed synthesis of $\mathrm{Au}_{25}(\mathrm{SR})_{18}$ nanoclusters. ACS Nano 6, 7920-7927 (2012).

101. Luo, Z. et al. Toward understanding the growth mechanism: tracing all stable intermediate species from reduction of $\mathrm{Au}(\mathrm{l})$-thiolate complexes to evolution of $\mathrm{Au}_{25}$ nanoclusters. J. Am. Chem. Soc. 136, 10577-10580 (2014).

102. Yao, Q. et al. Understanding seed-mediated growth of gold nanoclusters at molecular level. Nat. Commun. 8, 927 (2017).

103. Yao, Q. et al. Revealing isoelectronic size conversion dynamics of metal nanoclusters by a noncrystallization approach. Nat. Commun. 9, 1979 (2018).

104. Chen, T. et al. Synthesis of water-soluble $\left[\mathrm{Au}_{25}(\mathrm{SR})_{18}\right]^{-}$using a stoichiometric amount of $\mathrm{NaBH}_{4}$. J. Am. Chem. Soc. 140, 11370-11377 (2018).

105. Cao, Y. et al. Evolution of thiolate-stabilized Ag nanoclusters from Ag-thiolate cluster intermediates. Nat. Commun. 9, 2379 (2018).

106. Bootharaju, M. S., Joshi, C. P., Alhilaly, M. J. \& Bakr, O. M. Switching a nanocluster core from hollow to nonhollow. Chem. Mat. 28, 3292-3297 (2016).

107. Krishnadas, K. R. et al. Interparticle reactions: an emerging direction in nanomaterials chemistry. Acc. Chem. Res. 50, 1988-1996 (2017).

108. Krishnadas, K. R. et al. Intercluster reactions between $\mathrm{Au}_{25}(\mathrm{SR})_{18}$ and $\mathrm{Ag}_{44}(\mathrm{SR})_{30}$. J. Am. Chem. Soc. 138, 140-148 (2016).

109. Krishnadas, K. R., Baksi, A., Ghosh, A., Natarajan, G. \& Pradeep, T. Manifestation of geometric and electronic shell structures of metal clusters in intercluster reactions. ACS Nano 11, 6015-6023 (2017).

110. Krishnadas, K. R., Baksi, A., Ghosh, A., Natarajan, G. \& Pradeep, T. Structureconserving spontaneous transformations between nanoparticles. Nat. Commun. 7, 13447 (2016)

111. Salassa, G., Sels, A., Mancin, F. \& Bürgi, T. Dynamic nature of thiolate monolayer in $\mathrm{Au}_{25}(\mathrm{SR})_{18}$ nanoclusters. ACS Nano 11, 12609-12614 (2017).

112. Chakraborty, P. et al. Rapid isotopic exchange in nanoparticles. Sci. Adv. $\mathbf{5}$ eaau7555 (2019)

113. Chakraborty, P., Nag, A., Paramasivam, G., Natarajan, G. \& Pradeep, T. Fullerene-functionalized monolayer-protected silver clusters: $\left[\mathrm{Ag}_{29}(\mathrm{BDT})_{12}\left(\mathrm{C}_{60}\right)_{n}\right]^{3-}(\mathrm{n}=1-9)$. ACS Nano 12, 2415-2425 (2018).

114. Mathew, A. et al. Supramolecular functionalization and concomitant enhancement in properties of $\mathrm{Au}_{25}$ clusters. ACS Nano 8, 139-152 (2014).

115. Nag, A. et al. Isomerism in supramolecular adducts of atomically precise nanoparticles. J. Am. Chem. Soc. 140, 13590-13593 (2018).

116. Niihori, Y., Uchida, C., Kurashige, W. \& Negishi, Y. High-resolution separation of thiolate-protected gold clusters by reversed-phase high-performance liquid chromatography. Phys. Chem. Chem. Phys. 18, 4251-4265 (2016).

117. Black, D. M., Bhattarai, N., Bach, S. B. H. \& Whetten, R. L. Selection and identification of molecular gold clusters at the nano(gram) scale: reversed phase HPLC-ESI-MS of a mixture of Au-Peth MPCs. J. Phys. Chem. Lett. 7, 3199-3205 (2016).

118. Black, D. M., Bach, S. B. H. \& Whetten, R. L. Capillary liquid chromatography mass spectrometry analysis of intact monolayer-protected gold clusters in complex mixtures. Anal. Chem. 88, 5631-5636 (2016).

119. Black, D. M. et al. Liquid chromatography separation and mass spectrometry detection of silver-lipoate $\mathrm{Ag}_{29}(\mathrm{LA})_{12}$ nanoclusters: evidence of isomerism in the solution phase. Anal. Chem. 90, 2010-2017 (2018). 
120. Kumara, C. et al. Super-stable, highly monodisperse plasmonic faradaurate500 nanocrystals with 500 gold atoms: $\mathrm{Au}_{\sim 500}(\mathrm{SR})_{\sim 120}$. J. Am. Chem. Soc. 136, 7410-7417 (2014).

121. Kumara, C., Zuo, X., Cullen, D. A. \& Dass, A. Faradaurate-940: synthesis, mass spectrometry, electron microscopy, high-energy $\mathrm{X}$-ray diffraction, and X-ray scattering study of $\mathrm{Au}_{\sim 940 \pm 20}(\mathrm{SR})_{\sim 160 \pm 4}$ nanocrystals. ACS Nano $\mathbf{8}$, 6431-6439 (2014).

122. Sakthivel, N. A., Theivendran, S., Ganeshraj, V., Oliver, A. G. \& Dass, A. Crystal structure of faradaurate-279: $\mathrm{Au}_{279}\left(\mathrm{SPh}-{ }^{\mathrm{t}} \mathrm{Bu}\right)_{84}$ plasmonic nanocrystal molecules. J. Am. Chem. Soc. 139, 15450-15459 (2017).

123. Kumara, C. et al. Isolation of a $300 \mathrm{kDa}, \mathrm{Au}_{\sim 1400}$ gold compound, the standard $3.6 \mathrm{~nm}$ capstone to a series of plasmonic nanocrystals protected by aliphatic-like thiolates. J. Phys. Chem. Lett. 9, 6825-6832 (2018).

124. Vergara, S. et al. Synthesis, mass spectrometry, and atomic structural analysis of $\mathrm{Au}_{\sim 2000}(\mathrm{SR})_{\sim 290}$ nanoparticles. J. Phys. Chem. C. 122, 26733-26738 (2018).

125. Yan, X., Bain, R. M. \& Cooks, R. G. Organic reactions in microdroplets: reaction acceleration revealed by mass spectrometry. Angew. Chem. Int. Ed. 55 12960-12972 (2016).

126. Ingram, A. J., Boeser, C. L. \& Zare, R. N. Going beyond electrospray: mass spectrometric studies of chemical reactions in and on liquids. Chem. Sci. 7, 39-55 (2016).

127. Sarkar, D. et al. Metallic nanobrushes made using ambient droplet sprays. Adv. Mat. 28, 2223-2228 (2016).

128. Baksi, A. et al. Monolayer-protected noble-metal clusters as potential standards for negative-ion mass spectrometry. Anal. Chem. 90, 11351-11357 (2018).

129. Seo, J., Warnke, S., Pagel, K., Bowers, M. T. \& von Helden, G. Infrared spectrum and structure of the homochiral serine octamer-dichloride complex. Nat. Chem. 9, 1263 (2017).

130. Warnke, S. et al. Protomers of benzocaine: solvent and permittivity dependence. J. Am. Chem. Soc. 137, 4236-4242 (2015).

131. Xavier, P. L., Chaudhari, K., Baksi, A. \& Pradeep, T. Protein-protected luminescent noble metal quantum clusters: an emerging trend in atomic cluster nanoscience. Nano Rev. 3, 14767 (2012).

132. Gwinn, E., Schultz, D., Copp, S. M. \& Swasey, S. DNA-protected silver clusters for nanophotonics. Nanomaterials 5, 180-207 (2015).

133. Chaudhari, K. Xavier, P. L. \& Pradeep, T. Understanding the evolution of luminescent gold quantum clusters in protein templates. ACS Nano 5, 8816-8827 (2011).

134. Barner-Kowollik, C., Gruendling, T., Falkenhagen, J. \& Weidner, S. Mass Spectrometry in Polymer Chemistry (Wiley-VCH Verlag GmbH \& Co. KGaA., Weinheim, Germany, 2012).

135. Dempster, A. J. A new method of positive ray analysis. Phys. Rev. 11, 316-325 (1918).

136. Arnot, F. L. \& Beckett, C. Formation of negative ions at surfaces. Nature 141, 1011 (1938).

137. Graus, M., Müller, M. \& Hansel, A. High resolution PTR-TOF: quantification and formula confirmation of VOC in real time. J. Am. Soc. Mass Spectrom. 21, 1037-1044 (2010).

138. Cody, R. B., Tamura, J. \& Musselman, B. D. Electrospray ionization/magnetic sector mass spectrometry: calibration, resolution, and accurate mass measurements. Anal. Chem. 64, 1561-1570 (1992).
139. E., S. W. A pulsed mass spectrometer with time dispersion. Phys. Rev. 69 674-674 (1946).

140. Johnson, E. G. \& Nier, A. O. Angular aberrations in sector shaped electromagnetic lenses for focusing beams of charged particles. Phys. Rev. 91, 10-17 (1953).

141. Wiley, W. C. \& McLaren, I. H. Time-of-flight mass spectrometer with improved resolution. Rev. Sci. Instrum. 26, 1150-1157 (1955).

142. Beynon, J. H. The use of the mass spectrometer for the identification of organic compounds. Microchim. Acta 44, 437-453 (1956).

143. Paul, W. Electromagnetic traps for charged and neutral particles. Rev. Mod. Phys. 62, 531-540 (1990)

144. McDaniel, E. W., Martin, D. W. \& Barnes, W. S. Drift tube-mass spectrometer for studies of low-energy ion-molecule reactions. Rev. Sci. Instrum. 33, 2-7 (1962).

145. Munson, M. S. B. \& Field, F. H. Chemical ionization mass spectrometry. I. general introduction. J. Am. Chem. Soc. 88, 2621-2630 (1966).

146. McLafferty, F. W. \& Bryce, T. A. Metastable-ion characteristics: characterization of isomeric molecules. Chem. Commun., 1215-1217 (1967).

147. Chernushevich, I. V., Merenbloom, S. I., Liu, S. \& Bloomfield, N. A W-Geometry ortho-TOF MS with high resolution and up to $100 \%$ duty cycle for MS/MS. J. Am. Soc. Mass Spectrom. 28, 2143-2150 (2017).

148. Weisbrod, C. R. et al. Front-end electron transfer dissociation coupled to a 21 Tesla FT-ICR mass spectrometer for intact protein sequence analysis. J. Am. Soc. Mass Spectrom. 28, 1787-1795 (2017).

149. Dole, M. et al. Molecular beams of macroions. J. Chem. Phys. 49, 2240-2249 (1968).

150. Horning, E. C. et al. Atmospheric pressure ionization (API) mass spectrometry. Solvent-mediated ionization of samples introduced in solution and in a liquid chromatograph effluent stream. J. Chromatogr. Sci. 12, 725-729 (1974).

151. Cooks, R. G., Terwilliger, D. T., Ast, T., Beynon, J. H. \& Keough, T. Surface modified mass spectrometry. J. Am. Chem. Soc. 97, 1583-1585 (1975).

152. Yost, R. A. \& Enke, C. G. Selected ion fragmentation with a tandem quadrupole mass spectrometer. J. Am. Chem. Soc. 100, 2274-2275 (1978).

153. Barber, M., Bordoli, R. S., Sedgwick, R. D. \& Tyler, A. N. Fast atom bombardment of solids (F.A.B.): a new ion source for mass spectrometry. J. Chem. Soc Chem. Commun., 325-327 (1981).

154. Karas, M., Bachmann, D., Bahr, U. \& Hillenkamp, F. Matrix-assisted ultraviolet laser desorption of non-volatile compounds. Int. J. Mass Spectrom. IonProcess. 78, 53-68 (1987).

155. Takáts, Z., Wiseman, J. M., Gologan, B. \& Cooks, R. G. Mass spectrometry sampling under ambient conditions with desorption electrospray ionization Science 306, 471 (2004).

156. Siuzdak, G. et al. Mass spectrometry and viral analysis. Chem. Biol. 3, 45-48 (1996).

157. Hendrickson, C. L. et al. 21 Tesla fourier transform ion cyclotron resonance mass spectrometer: a national resource for ultrahigh resolution mass analysis. J. Am. Soc. Mass Spectrom. 26, 1626-1632 (2015).

158. Ludwig, K., Habbach, S., Krieglstein, J., Klumpp, S. \& König, S. MALDI-TOF high mass calibration up to $200 \mathrm{kDa}$ using human recombinant $16 \mathrm{kDa}$ protein histidine phosphatase aggregates. PLoS One 6, e23612 (2011).

159. Aksenov, A. A. \& Bier, M. E. The analysis of polystyrene and polystyrene aggregates into the mega dalton mass range by cryodetection MALDI TOF MS. J. Am. Soc. Mass Spectrom. 19, 219-230 (2008). 